\title{
Treatment of nonpsychotic major depression during pregnancy: patient safety and challenges
}

\author{
This article was published in the following Dove Press journal: \\ Drug, Healthcare and Patient Safety \\ 18 September 2014 \\ Number of times this article has been viewed
}

\author{
Richard A Epstein' \\ Katherine M Moore ${ }^{2}$ \\ William $\vee$ Bobo ${ }^{2}$ \\ 'Department of Psychiatry, Vanderbilt \\ University School of Medicine, \\ Nashville, TN, ${ }^{2}$ Department of \\ Psychiatry and Psychology, Mayo \\ Clinic, Rochester, MN, USA
}

\begin{abstract}
In pregnant women with major depression, the overarching goal of treatment is to achieve or maintain maternal euthymia, thus limiting both maternal and fetal exposure to the harmful effects of untreated or incompletely treated depression. However, the absence of uniformly effective therapies with guaranteed obstetric and fetal safety makes the treatment of major depression during pregnancy among the most formidable of clinical challenges. Clinicians and patients are still faced with conflicting data and expert opinion regarding the reproductive safety of antidepressants in pregnancy, as well as large gaps in our understanding of the effectiveness of most antidepressants and nonpharmacological alternatives for treating antenatal depression. In this paper, we provide a clinically focused review of the available information on potential maternal and fetal risks of untreated maternal depression during pregnancy, the effectiveness of interventions for maternal depression during pregnancy, and potential obstetric, fetal, and neonatal risks associated with antenatal antidepressant use.
\end{abstract}

Keywords: depression, major depressive disorder, pregnancy, antidepressants, safety

\section{Introduction}

Major depression and other unipolar depressive syndromes are highly prevalent and disproportionately affect women. ${ }^{1,2}$ The peak incidence of major depression in women is during the reproductive years, ${ }^{3}$ raising the possibility of depressive episode onset (or relapse in women already diagnosed with major depression) during pregnancy. Indeed, the prevalence of any depressive illness during pregnancy is estimated at $18.4 \%(7.3 \%$ for major depressive disorder during pregnancy). ${ }^{4}$ Rates of mood-disorder onset in women are roughly equivalent between pregnant and nonpregnant samples, ${ }^{5,6}$ and the frequency of major depression during the second and third trimesters may even exceed that of the general population. ${ }^{7}$

Although major depression and other depressive illnesses cannot be cured at present, their symptoms can be controlled in most patients with focused psychotherapy, appropriate pharmacotherapy, or the combination of the two. ${ }^{8}$ In pregnant women with major depression, the overarching goal of treatment is to achieve or maintain maternal euthymia, thus limiting both maternal and fetal exposure to the harmful effects of untreated or incompletely treated depression. Ideally, this would be achieved using treatment modalities that have no possibility of harming the pregnancy or developing fetus. Effective nonpharmacological modalities may achieve these aims for many, but not all, women with depression. Indeed, a considerable number of women benefit from antidepressant treatments for achieving or maintaining euthymia during pregnancy. On the other hand, the use of antidepressants for treating maternal depression and other
Department of Psychiatry, Vanderbit University School of Medicine, Suite 2200, Village at Vanderbilt, 15002 Ist Avenue South, Nashville, TN 37212 , USA Tel + I 6I5 3434497

Fax + I 6I5 3221578

Email richard.a.epstein@vanderbilt.edu 
disorders during pregnancy has increased steadily in the last two decades, ${ }^{9-13}$ which has raised concerns about the risks versus benefits of this practice.

The absence of uniformly effective therapeutics with guaranteed obstetric and fetal safety makes the treatment of major depression during pregnancy among the most formidable of clinical challenges. ${ }^{14}$ Clinical practice guidelines can provide direction, but to follow these guidelines clinicians must translate estimates of treatment effectiveness and risk from rapidly evolving population-level data to individual patients, taking into account each patient's tolerance of risk related to both the underlying illness and available interventions. ${ }^{15,16}$ Clinicians and patients are still faced with conflicting data and expert opinion regarding the reproductive safety of antidepressants in pregnancy, as well as gaps in our understanding of the effectiveness of most antidepressants and nonpharmacological alternatives for treating antenatal depression. This paper provides a clinically focused review of the available information on risks of untreated maternal depression during pregnancy, effectiveness of interventions for maternal depression during pregnancy, and potential harms of treatments for maternal depression during pregnancy, and presents recommendations for treating maternal depression during pregnancy.

\section{Materials and methods}

Relevant studies were identified via a Medline/PubMed search of the literature for reports and studies for the period beginning in 1996 and ending in 2013. Potential harms of interest included congenital malformations, adverse neonatal events, and obstetric complications. We used combinations of keywords that defined antidepressant exposures (antidepressants, selective serotonin-reuptake inhibitors [SSRIs], fluoxetine, fluvoxamine, paroxetine, sertraline, citalopram, escitalopram, venlafaxine, desvenlafaxine, duloxetine, bupropion, tricyclic antidepressants [TCAs], imipramine, desipramine, amitriptyline, nortriptyline, clomipramine, protriptyline, trimipramine, doxepin, monoamine oxidase inhibitors, phenelzine, tranylcypromine, isocarboxazid, mirtazapine, nefazodone, and vilazodone) with those that defined outcomes of interest (pregnancy outcome [congenital, fetal], birth outcome, malformations, congenital malformations, birth defects, cardiac/heart defects, persistent pulmonary hypertension of the newborn [PPHN], and neurobehavioral outcomes). Vortioxetine was not included because of its very recent regulatory approval. Milnacipran was not included because of its approval for treating fibromyalgia syndrome and limited clinical use for treating major depression. A similar approach was used to locate reports addressing benefits and harms of nonpharmacological treatments (psychotherapy, interpersonal therapy [IPT], cognitive behavioral therapy [CBT], electroconvulsive therapy [ECT], repetitive transcranial magnetic stimulation [rTMS], exercise, bright-light therapy [luminotherapy], therapeutic massage, and acupuncture). Systematic reviews, meta-analyses, randomized trials, and observational studies were reviewed. Additional papers and abstracts were retrieved from the bibliographic sections of review papers and individual reports. Throughout the paper, we generally refer to maternal depression during pregnancy as "antenatal depression" (as opposed to "antenatal major depression"), because several of the reviewed studies included persons with clinically significant depressive symptoms but unconfirmed major depressive disorder diagnoses and because of variability in diagnostic methods across studies restricted to major depression.

\section{Results}

\section{Clinical impact of antenatal depression}

Antenatal depression has been linked with worse general health status; poor maternal self-care during pregnancy; underutilization of prenatal care; increased maternal use of cigarettes, alcohol, and other abused substances; isolation or withdrawal from family or other supports; and increased risk of postpartum depression and maternal suicide, ${ }^{17-23}$ the latter of which may account for up to $20 \%$ of postpartum deaths. ${ }^{24}$ Other potential risks of untreated antenatal depression include poor nutrition intake during pregnancy, severe fatigue, and lack of motivation for self-care. ${ }^{25}$ Women with depression or other psychiatric disorders for which antidepressants are often prescribed are less likely to get appropriate prenatal and pediatric care, which may increase the risk of increased postneonatal morbidity. ${ }^{26,27}$

Untreated or undertreated antenatal depression has also been associated with a variety of adverse obstetric and neonatal outcomes, including preeclampsia and eclampsia, ${ }^{28,29}$ miscarriage, ${ }^{30}$ preterm birth or shorter gestational length, ${ }^{6,30-32}$ poor fetal and infant growth, ${ }^{33-35}$ low infant birth weight/small for gestational age, ${ }^{6,30,31,36,37}$ and low Apgar scores. ${ }^{38}$ A recent meta-analysis of 30 heterogeneous studies showed a modest association between antenatal depression and increased risk of premature delivery (odds ratio [OR] 1.37, 95\% confidence interval [CI] 1.04-1.81) and decreased likelihood of breastfeeding initiation (OR 0.68, 95\% CI 0.61-0.76). ${ }^{39}$ The meta-analysis did not demonstrate a statistically significant increased risk of most other perinatal outcomes in association with antenatal depression; however, antenatal 
depression was significantly but modestly associated with low birth weight (OR 1.39, 95\% CI 1.00-1.94) and preeclampsia (OR 2.50, 95\% CI 1.13-5.54) after restricting the analyses to adjusted data.

Maternal depression during pregnancy or the postpartum period has been associated with impaired mother-infant attachment and developmental difficulties in offspring. ${ }^{40}$ Children exposed to untreated antenatal depression are at higher risk for developmental delay, impaired language development, and lower intelligence quotient (IQ) scores, ${ }^{41-43}$ and poor socioemotional development, including worse emotional regulation and higher rates of depressive and anxiety symptoms. ${ }^{44-46}$ Others have shown that approximately a third of school-age children experience depressive, anxiety, or disruptive disorders while their mother is depressed. ${ }^{47}$

On the other hand, successful treatment of antenatal depression is associated with reduced psychiatric symptoms and diagnoses in their children. In a cohort of 151 motherchild pairs who participated in the STAR*D-Child (Sequenced Treatment Alternatives to Relieve Depression - Child) study, remission of maternal depression after 3 months of medication treatment occurred in $33 \%$ of subjects ${ }^{48}$ and was associated with an $11 \%$ decrease in the rates of an affective, anxiety, or disruptive behavior disorders in offspring (aged 7-17 years), as assessed by the Kiddie Schedule for Disorders and Schizophrenia. Continuing depression was associated with an $8 \%$ increase in the rates of these diagnoses. The relationship between improvement in maternal depression and lower rates of child psychopathology and functioning were still apparent after 1 year of follow-up. ${ }^{49}$

\section{Effectiveness of treatments for antenatal depression}

Clinicians, patients, and their families have a wide range of treatments from which to choose. Common treatments include pharmacotherapy, psychotherapy, and other therapies.

\section{Pharmacotherapy}

The effectiveness of antidepressants for treating antenatal depression or preventing depressive relapse in women with depression during pregnancy has received limited investigation. In a nonrandomized, multicenter, prospective study of 201 antidepressant-treated patients (161 [81.1\%] of whom were treated with SSRIs) recruited from specialty mental health treatment settings who were euthymic for at least 3 months prior to study entry, Cohen et al reported that discontinuation of antidepressants during pregnancy was associated with more frequent relapses (68\% versus $26 \%$ ) compared with women who continued their medication. ${ }^{50}$ Women who stopped effective antidepressant treatment had five times the risk of relapse. Of those who stopped antidepressant treatment but restarted medication, the overall risk of relapse was also decreased, but to a smaller degree than patients who received continuous treatment throughout pregnancy. Lowering the dose of antidepressant did not reduce the risk of relapse. Relapses occurred more often in depressed patients with markers of more severe illness, including longer duration of illness, greater number of lifetime episodes, history of suicidal ideation, and family history of depressive illness.

A small prospective cohort study of 238 depressed pregnant women, 71 of whom were treated with SSRIs, reported that mean depressive symptom levels (as measured by the 29-item Structured Interview Guide for the Hamilton Depression Rating Scale with Atypical Depression Supplement and the 17-item version of the Hamilton Depression Rating Scale) in women with continuous depression during pregnancy and no SSRI treatment were significantly greater than exposure groups that consisted of depressed women who received SSRI treatment. The study authors suggest that the results were consistent with the "expected treatment effects of SSRIs", presumably in comparison with nonpuerperal major depression. ${ }^{51}$

It is currently unclear if antidepressant effectiveness is the same for treating puerperal and nonpuerperal major depression, and questions remain regarding the effectiveness of antidepressant treatment for preventing depressive relapses during pregnancy in women with established diagnoses of major depression. ${ }^{15}$ In the Cohen et al study, women who chose to continue an effective antidepressant throughout pregnancy still had a $26 \%$ risk of relapse during follow-up. ${ }^{50}$ Moreover, in a well-controlled study of 778 women with a history of any depressive disorder (as determined by lay interviewers using the Composite International Diagnostic Interview) who were recruited from obstetric rather than specialty mental health care settings, the risk of a major depressive episode during pregnancy did not differ statistically between women who took antidepressants and those who did not (hazard ratio $0.85,95 \%$ CI $0.52-1.40) .{ }^{52}$ The overall rate of major depressive episode onset during pregnancy was $16 \%$, though differences by antidepressant exposure in rates of depressive episode occurrence were not reported, and the analyses were not stratified by depression severity or presence of comorbid illnesses, such as anxiety disorders.

Therefore, it seems clear that some pregnant women with antenatal depression will benefit from antidepressant treatment, but a substantial proportion of patients will not. This is 
broadly consistent with findings from studies of antidepressant effectiveness in the broader population of patients with nonpuerperal major depression. Comparative effectiveness studies of antidepressants for treating antenatal depression are lacking, and additional studies are needed to determine the effectiveness of antidepressants for treating antenatal depression across treatment settings. This would not only permit better estimates of antidepressant effectiveness overall and by individual agent, but would also have the potential to inform clinical practice by helping determine which patients are most likely to benefit from specific antidepressant medications during pregnancy.

\section{Psychotherapy}

There is evidence from controlled studies that systematically oriented psychotherapies, such as IPT and CBT, may be effective for treating antenatal depression or clinically significant depressive symptoms that occur during pregnancy.

\section{Interpersonal therapy}

A recent meta-analysis of 24 studies (18 of which focused on individual IPT and six of which focused on relational therapies) in pregnant or postpartum women with depression demonstrated significant positive effects on depressive symptoms. ${ }^{53}$ Treatment-effect sizes were larger with individual IPT than relational therapies (such as marital and family therapies). Interventions that included an IPT component were also found to have greater effect sizes for reducing depressive symptom levels in another systematic review and meta-analysis of 27 heterogeneous studies that examined the effectiveness of pharmacologic and psychological interventions for unipolar depression during pregnancy or the postpartum. ${ }^{54}$ Partner-assisted IPT, a form of IPT that was specifically developed for perinatal depression, showed promising results in a preliminary proof-of-concept trial in women with antenatal or postpartum depression. ${ }^{55}$

\section{Cognitive behavioral therapy}

Although CBT is an established treatment for mild-tomoderate nonpuerperal major depression, far less is known about its effectiveness for treating antenatal depression. The same meta-analysis of 27 heterogeneous studies reviewed earlier found CBT to be beneficial for perinatal depression, albeit with small-to-medium effects. ${ }^{54}$ In a randomized trial, CBT adapted for perinatal depression in outpatients was associated with greater improvement in depressive symptoms than standard care over 16 weeks of follow-up. ${ }^{56}$ Most individual trials of CBT for perinatal depression have focused on the treatment of postpartum depression. ${ }^{57-59}$ Therefore, additional investigations of the effectiveness of CBT for treating antenatal depression are needed.

\section{Other psychotherapies}

Difficulties with marital, family, and other important relationships are common complications of mood disorders in general, and are robust predictors of depression during pregnancy and the postpartum period. ${ }^{60}$ It is therefore surprising that there has been so little investigation of the effectiveness of relational therapies (focused on marital and family problems) for treating antenatal depression. One meta-analysis reviewed earlier showed lower effect sizes with relational therapies than IPT in women with antenatal depression; ${ }^{53}$ however, it seems reasonable that cases of maternal depression in which marital and family problems contribute heavily to depressive symptom burden may also stand to benefit most from these interventions as well as IPT. The effectiveness of psychodynamic psychotherapy and psychoanalytic approaches in this population is described only in case literature. ${ }^{61}$

\section{Other nonpharmacological interventions}

\section{Exercise}

Physical exercise during pregnancy is associated with improved cardiorespiratory fitness and other health benefits, without evidence of harm to the newborn. ${ }^{62}$ While not generally considered to be a stand-alone treatment for depression, exercise has been shown to help alleviate symptoms of major depression in nonpregnant samples. ${ }^{63-65}$ One study showed that supervised aerobic exercise commenced at 16-20 weeks gestation and extended over 3 months resulted in reduced depressive symptoms in nulliparous women with no psychiatric history. ${ }^{66}$ Results of two small studies suggest that significant decreases in depressive symptoms can occur in women who were previously inactive.$^{67,68}$ Controlled studies of the benefits of exercise as either a primary or adjunctive intervention for treating antenatal depression are needed.

\section{Luminotherapy}

Luminotherapy, or bright-light therapy, is effective for seasonal and nonseasonal depression, though effect sizes for nonseasonal depression are smaller. ${ }^{69,70}$ In an open trial of 16 women with antenatal depression, early morning bright light (60 minutes at 10,000 1x) was associated with a $49 \%$ decrease in depressive symptoms over 3 weeks. ${ }^{71}$ Further improvement was observed in seven patients who continued early morning bright-light therapy for 5 weeks. An initial randomized trial of ten patients with antenatal 
depression showed a higher positive response rate with luminotherapy delivered at 7,000 $\mathrm{lx}$ than a placebo condition consisting of subtherapeutic light exposure (60\% versus $41 \%)$; however, these differences were not statistically significant. ${ }^{72}$ In a larger randomized trial, significantly higher rates of positive treatment response were observed with luminotherapy (7,000 lx bright light) than placebo (70 1x dim red light) over 5 weeks ( $81.3 \%$ versus $45.5 \%) .{ }^{73}$ Large, randomized trials are needed to establish the antidepressive effect of luminotherapy for treating antenatal depression.

\section{Repetitive transcranial magnetic stimulation}

One open-label study of ten women with antenatal depression who received 20 daily rTMS treatments, with or without concomitant antidepressants, showed a $70 \%$ positive treatmentresponse rate. ${ }^{74} \mathrm{~A}$ larger study of 30 antenatally depressed patients who received rTMS over the left prefrontal cortex (6 days weekly for 3 weeks) showed significant reduction from baseline in Hamilton Depression Rating Scale scores. Rates of response and remission were $41.4 \%$ and $20.7 \%$, respectively. ${ }^{75}$ No adverse pregnancy or fetal outcomes were reported in either study. Randomized trials are needed to establish the antidepressive effect of rTMS for treating antenatal depression.

\section{Electroconvulsive therapy}

ECT is an established therapeutic modality for severe, catatonic, or psychotic depression, where rapid antidepressive effects are urgently required and lag time to therapeutic benefit associated with pharmacotherapy may be unacceptable. Extensive case-series data provide much of the rationale for the effectiveness and safety of ECT during pregnancy. ${ }^{76,77}$ Although ECT has been used safely during all three trimesters of pregnancy and no consistent patterns of fetal or birth complications have been reported, ${ }^{76,78}$ the anesthetic agents and neuromuscular blockers that are commonly employed as part of modern ECT techniques undergo transplacental passage, and case literature suggests that reduced fetal heart rate, uterine contractions, and premature labor may be adverse effects of ECT given in late pregnancy. ${ }^{79}$ Randomized trials are lacking.

\section{Complementary/alternative medicine treatments}

There are very few high-quality studies of massage therapy, acupuncture, and hypnosis for treating antenatal depression. ${ }^{80,81}$ One randomized trial compared acupuncture (specific for depression), control acupuncture, and massage for 8 weeks in 150 women with antenatal depression. Acupuncture specific for depression was associated with significantly greater reduction in depressive symptoms than control acupuncture alone, or the two control conditions combined. ${ }^{82}$ Rates of positive treatment response were also significantly higher with acupuncture specific for depression $(63.0 \%)$ than the combined control conditions (44.3\%).

\section{Potential harms of treatments for maternal depression}

Potential harms of treatments for maternal depression have been best studied with respect to pharmacotherapies in general and antidepressants in particular. Therefore, the current review focuses on antidepressant pharmacotherapy. Table 1 presents a summary of the current US Food and Drug Administration (FDA) pregnancy-safety categories and listing of the safety category for commonly used antidepressants. Much less is known about the risks and benefits of psychotherapy or other therapies for antenatal depression.

\section{Major congenital malformations}

Major congenital malformations (MCMs) refer to structural defects present at birth that are associated with significant medical or cosmetic problems. In the US general population, the risk of MCMs is about one in every 33 infants $(\sim 3 \%) .{ }^{83}$ The majority of birth defects have no known etiology, while approximately a quarter are attributed to genetic, chromosomal, or cytogenetic disorders. ${ }^{84}$ Only $2 \%-3 \%$ of birth defects are classified as teratogen-induced. ${ }^{84}$ For most MCMs, the sensitive period during embryonic development occurs during the 3-8 weeks after conception, or 5-10 weeks after the last maternal menstrual period. Teratogenic drugs act by drug-specific mechanisms on developing cells and tissues, and will typically cause organ-specific defects in a consistent pattern, rather than "any" malformation. ${ }^{85}$

Prior to 2000, small prospective studies showed no increased risk of MCMs in humans after in utero exposure to SSRIs, ${ }^{86-90}$ the most common type of antidepressant used during pregnancy. ${ }^{91}$ However, most MCMs are rare events, and prospective studies generally lack sufficient statistical power to detect subtle but potentially important increases in teratogenic risk. Very large observational studies using pregnancy registries or automated health outcome databases can provide useful information for estimating drug-MCM associations for antidepressants.

Most individual studies have considered fetal exposure to antidepressants as a single group or in broad classes (SSRIs, etc). The majority of individual studies have not 
Table I Summary of the current US Food and Drug Administration (FDA) pregnancy safety categories

\begin{tabular}{|c|c|c|}
\hline Category & Definition & Antidepressants by FDA pregnancy-safety category \\
\hline A & $\begin{array}{l}\text { Adequate and well-controlled studies in pregnant women have } \\
\text { not demonstrated fetal risk with exposure in the first trimester } \\
\text { of pregnancy, and there is no evidence of risk with exposure in } \\
\text { the second or third trimesters. }\end{array}$ & None \\
\hline B & $\begin{array}{l}\text { There are no adequate and well-controlled studies in pregnant } \\
\text { women, and animal studies have not shown evidence of fetal risk. }\end{array}$ & Tetracyclic antidepressants: maprotiline \\
\hline C & $\begin{array}{l}\text { There are no adequate and well-controlled studies in pregnant } \\
\text { women, but animal studies have shown evidence of fetal risk. } \\
\text { For pregnant women, potential benefits may warrant use of the } \\
\text { medication in pregnant women despite possible risks. }\end{array}$ & $\begin{array}{l}\text { SSRIs: citalopram, escitalopram, fluoxetine, fluvoxamine, } \\
\text { sertraline } \\
\text { SNRIs: desvenlafaxine, duloxetine, venlafaxine } \\
\text { TCAs: amitriptyline, amoxapine, clomipramine, doxepin, } \\
\text { trimipramine } \\
\text { MAOIs: isocarboxazid, phenelzine, selegiline, tranylcypromine } \\
\text { Miscellaneous: bupropion, mirtazapine, nefazodone, } \\
\text { trazodone, vilazodone, vortioxetine }\end{array}$ \\
\hline D & $\begin{array}{l}\text { There is positive evidence of human fetal risk based on } \\
\text { investigational or postmarketing experience, but potential } \\
\text { benefits may warrant use of the medication in pregnant women } \\
\text { despite possible risks. }\end{array}$ & $\begin{array}{l}\text { SSRIs: paroxetine } \\
\text { TCAs: imipramine, nortriptyline }\end{array}$ \\
\hline$x$ & $\begin{array}{l}\text { Animal or human studies have shown fetal abnormalities and/or } \\
\text { there is positive evidence of human fetal risk based on } \\
\text { investigational or postmarketing experience; risks from the } \\
\text { medication clearly outweigh potential benefit. }\end{array}$ & None \\
\hline$N$ & The FDA has not classified the medication. & TCAs: desipramine, protriptyline \\
\hline
\end{tabular}

Abbreviations: SSRIs, selective serotonin-reuptake inhibitors; SNRIs, serotonin-norepinephrine reuptake inhibitors; TCAs, tricyclic antidepressants; MAOIs, monoamine oxidase inhibitors.

demonstrated increased risk of MCMs associated with antidepressant exposure in the first trimester or at any time during pregnancy. ${ }^{87,89,92-104}$ Meta-analyses of studies investigating the risk of antidepressants and "any" or "overall" MCMs have shown either small but statistically significant risk ${ }^{105,106}$ or absence of significant increase in risk (Table 2). ${ }^{107-110}$

Studies with larger cohorts have shown an association between first trimester antidepressant exposure and congenital heart defects, particularly septal defects. ${ }^{93,94,98,111-117}$ Although these results have not been replicated in several other studies, ${ }^{51,87,90,97,100,118-124}$ a small increase in the risk of any cardiac malformation or septal heart defect has been consistently reported across meta-analyses (Table 3), particularly for paroxetine, ${ }^{105-107}$ and in one case fluoxetine. ${ }^{108} \mathrm{An}$ increased risk of heart defects when SSRIs were combined with benzodiazepines during pregnancy compared with no first trimester exposure to drugs in either class (adjusted rate difference $=1.18 \%, 95 \%$ CI $0.18 \%-2.18 \%$ ) has also been reported. ${ }^{115}$ Neither drug class was associated with increased risk of heart defects when given individually.

Fewer studies of MCM risk with first trimester exposure to non-SSRI antidepressants exist. One analysis of birth registry data from Sweden examined the risk of congenital heart defects associated with maternal antidepressant use, including the use of TCAs, SSRIs, and serotonin- norepinephrine reuptake inhibitors (SNRIs), during early pregnancy, and reported an increased risk of ventricular or atrial septal defects with clomipramine (OR 2.22, 95\% CI 1.29-3.82) and paroxetine (OR 2.29, 95\% CI 1.28-4.09). ${ }^{117}$ These results supported earlier findings by the same authors of an increased risk for any cardiovascular defect associated with early pregnancy exposure to TCAs, primarily clomipramine (OR 1.77, 95\% CI 1.07-2.91). ${ }^{125} \mathrm{~A}$ third study by the same group reported an increased risk of congenital heart disease in the offspring of 1,029 women who reported use of clomipramine during early pregnancy (OR 1.87, 95\% CI 1.16-2.99).$^{98}$ Very little information on the teratogenic risk associated with other TCAs is available, though most studies have been negative. ${ }^{126} \mathrm{~A}$ report from the Bupropion Pregnancy Registry maintained by the drug manufacturer documented birth outcomes among 1,213 infants with first trimester bupropion exposure, and showed no increase in the risk of any congenital malformation compared with other antidepressant exposures in the first trimester, or with bupropion exposure outside of the first trimester. ${ }^{121}$ Thus far, studies of venlafaxine and mirtazapine have not shown increased risk of congenital malformations. ${ }^{95,127,128}$

The potential for confounding by indication and detection bias in studies of antidepressant use during pregnancy and MCM risk has received intense focus. At least one very 
Table 2 Meta-analyses of observational studies of antenatal AD use and the risk of congenital malformations

\begin{tabular}{|c|c|c|c|c|}
\hline Reference & Studies, n & Exposure groups & Main results & Confounding and bias \\
\hline $\begin{array}{l}\text { Myles } \\
\text { et al }{ }^{105}\end{array}$ & $\begin{array}{l}\text { Major malformations: I6 } \\
\text { Minor malformations: } 4\end{array}$ & $\begin{array}{l}\text { SSRI, first trimester } \\
(n=23,919) \\
\text { No SSRI }\end{array}$ & $\begin{array}{l}\text { Any malformation: all SSRIs, } \\
\text { OR I.I0 (95\% CI I.03-I.I6); } \\
\text { paroxetine, OR I.29 (95\% Cl } \\
\text { I.II-I.49); fluoxetine, OR I.I4 } \\
\text { (95\% CI I.0I-I.30); sertraline, } \\
\text { OR I.0I (95\% Cl 0.88-I.I7); } \\
\text { citalopram, OR I.04 (95\% Cl } \\
0.92-I . I 7)\end{array}$ & $\begin{array}{l}\text { Separate analyses conducted for studies that } \\
\text { considered early versus continuous SSRI } \\
\text { exposure; controlled for tobacco, alcohol, or } \\
\text { illicit drug use; controlled for maternal age; } \\
\text { controlled for maternal parity; and exclusion } \\
\text { of chromosomal or genetic abnormalities. }\end{array}$ \\
\hline $\begin{array}{l}\text { Grigoriadis } \\
\text { et al }{ }^{107}\end{array}$ & 12 & $\begin{array}{l}\text { Any AD }(n=|7,9| 5) \\
\text { No AD }\end{array}$ & $\begin{array}{l}\text { Any malformation: RR } 0.93 \\
\text { (95\% Cl 0.85-I.02) } \\
\text { Major malformations: RR I.07 } \\
(95 \% \mathrm{Cl} 0.99-1.17)\end{array}$ & $\begin{array}{l}\text { Systematic Assessment of Quality in } \\
\text { Observational Research (SAQOR) tool used } \\
\text { to evaluate individual study quality. }\end{array}$ \\
\hline $\begin{array}{l}\text { Riggin } \\
\text { et al }{ }^{108}\end{array}$ & 21 & $\begin{array}{l}\text { Fluoxetine, first trimester } \\
\text { (cohort studies, } \mathrm{n}=1 \mathrm{I}, 225 \text {; } \\
\text { case-control studies, } \\
\mathrm{n}=9,800 \text { ) }\end{array}$ & $\begin{array}{l}\text { Any malformation: cohort } \\
\text { studies, OR I.I2 ( } 95 \% \mathrm{Cl} \\
0.98-1.28) \text {; case-control studies, } \\
\text { OR } 3.72(95 \% \mathrm{Cl} 0.74-18.79)\end{array}$ & \\
\hline $\begin{array}{l}\text { Bar-Oz } \\
\text { et al }{ }^{106}\end{array}$ & 6 & $\begin{array}{l}\text { Paroxetine, first } \\
\text { trimester }(n=2,62 I) \\
\text { No paroxetine AD } \\
\text { exposure } \\
\text { No teratogen exposure }\end{array}$ & $\begin{array}{l}\text { Paroxetine versus other AD or } \\
\text { known nonteratogens: } \\
\text { Any malformation: OR I.3I } \\
\text { (95\% Cl I.03-I.67) } \\
\text { Paroxetine versus other AD: } \\
\text { Any malformation: OR } 1.30 \\
\text { (95\% Cl 0.92-I.80) } \\
\text { Paroxetine versus known } \\
\text { nonteratogens: } \\
\text { Any malformation: OR I.54 } \\
(95 \% \mathrm{Cl} 0.99-2.4 \mathrm{I})\end{array}$ & $\begin{array}{l}\text { Diagnostic tests in pregnancy: } \\
\text { Significantly greater use in AD users versus } \\
\text { nonusers; no significant difference between } \\
\text { paroxetine and other AD, using population- } \\
\text { based registry data. } \\
\text { Diagnostic tests in infancy: } \\
\text { Significantly higher rates of echocardiograms } \\
\text { with in utero SSRI exposure versus no AD } \\
\text { exposure, using population-based registry data. } \\
\text { Indication: } \\
\text { Significantly higher proportion of use for anxiety } \\
\text { disorders with paroxetine versus other SSRIs. }\end{array}$ \\
\hline $\begin{array}{l}\text { Rahimi } \\
\text { et al }{ }^{109}\end{array}$ & 9 & $\begin{array}{l}\text { SSRI, any exposure during } \\
\text { pregnancy }(n=I, 102) \\
\text { Unexposed to SSRI }\end{array}$ & $\begin{array}{l}\text { Any major malformation: } \\
\text { OR I.39 ( } 95 \% \text { Cl 0.9I-2.I5) }\end{array}$ & \\
\hline $\begin{array}{l}\text { Addis } \\
\text { et } \text { al }^{110}\end{array}$ & 4 & $\begin{array}{l}\text { Fluoxetine, first trimester } \\
(n=367)\end{array}$ & $\begin{array}{l}\text { Any major malformation: } \\
\text { weighted average } 2.6 \% \\
(95 \% \mathrm{Cl} 1 \%-4.2 \%)\end{array}$ & \\
\hline
\end{tabular}

Abbreviations: SSRI, selective serotonin-reuptake inhibitor; OR, odds ratio; $\mathrm{Cl}$, confidence interval; RR, relative risk; AD, antidepressant.

large population-based study suggested that the apparent increase in cardiac malformation risk associated with SSRIs also existed among depressed women who did not undergo drug treatment. ${ }^{116}$ However, this point remains controversial, because of findings from other studies that suggest that SSRIs, not maternal depression, may account for complications. ${ }^{6}$ One report has raised the possibility that higher risk of cardiac defects with paroxetine and other SSRIs may be due to detection bias. In that study, women who took SSRIs during pregnancy had 30\% more prenatal ultrasound exams than women who did not take an antidepressant, while infants who had been exposed to SSRIs during pregnancy had twice as many echocardiograms in the first year of life than unexposed infants. ${ }^{106}$

In summary, antidepressants in general and SSRIs more specifically have not been consistently associated with an increased risk of major congenital malformations overall.
However, there appears to be a small but statistically significant risk for cardiovascular malformations (mainly septal defects) with some individual agents, such as paroxetine, and possibly also fluoxetine. Contradictory findings and additional factors make the overall literature difficult to translate to clinical practice. For example, the absolute risk with SSRIs for any cardiovascular malformation appears small, and may be susceptible to confounding (including confounding by indication) and detection bias. ${ }^{99,129}$ Even if the relationship between SSRIs and heart defects is causal, it is still not established if any specific agents are clearly safer than others, although paroxetine and fluoxetine have been most implicated as having higher risk than other SSRIs. Moreover, grouping together all cardiovascular or cardiac defects limits clinical translation because of the wide variety of defects under consideration that are expressed along a broad spectrum of severity and medical risk. It is unclear, for instance, 


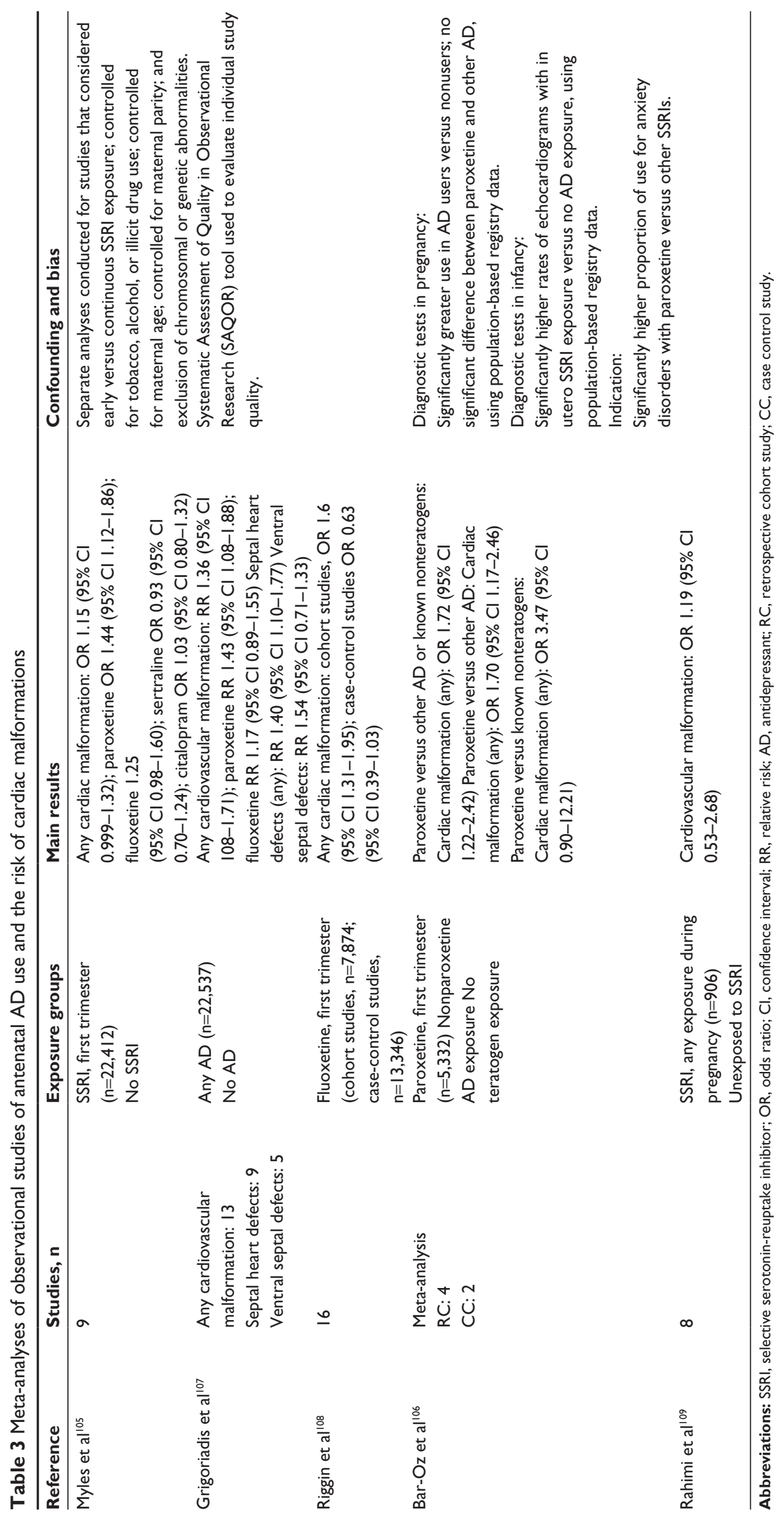


if SSRIs are associated with the development of more severe forms of septal defects, including those requiring surgical management, or if in utero exposure to antidepressants affects rates of spontaneous septal defect closure. For non-SSRI antidepressants, MCM-risk estimates are even less clear. A potential relationship between clomipramine exposure and fetal cardiac defects requires further examination.

\section{Minor congenital malformations}

The term "minor congenital malformation" refers to congenital birth defects that have no major surgical or cosmetic importance. Very few studies to date have focused on the risk of minor congenital malformations associated with antidepressant use during pregnancy. Chambers et al reported no significant association between antenatal fluoxetine use and MCMs, ${ }^{101}$ but also reported an increased number of exposed neonates that manifested three or more minor congenital anomalies. In a subsequent paper by Wisner et al, neither exposure to SSRIs nor maternal depression was associated with increased risk of minor physical anomalies. ${ }^{51}$ A recent meta-analysis of heterogeneous studies (2,631 exposed pregnancies) showed no statistically significant increase in the risk of minor congenital malformations with SSRIs (OR 1.16, 95\% CI 0.79-1.71). ${ }^{105}$ The small overall sample size did not permit additional analyses of risk by individual drug.

Results of existing studies of antidepressants and the risk of minor congenital malformations can be interpreted as reassuring thus far. Although the medical significance of a given minor malformation may be limited, they are not medically inconsequential. Some minor malformations serve as risk markers for the presence of an occult MCM, particularly if three or more minor malformations are present. ${ }^{130}$ As such, additional studies of minor congenital malformation risk associated with maternal use of antidepressants during pregnancy are needed.

\section{Adverse neonatal events}

\section{Persistent pulmonary hypertension of the newborn}

PPHN is caused by a failure of normal circulatory transition from a state of relatively high pressure in the pulmonary circulation before birth (to facilitate gas exchange at the placenta) to normal pulmonary artery pressure after delivery (to facilitate pulmonary gas exchange). If the normal decrease in pulmonary vascular tone does not occur, PPHN leading to hypoxemia results because of continued shunting of blood away from the lungs. Although PPHN is rare (one to two cases per 1,000 live births), severe cases are life-threatening. ${ }^{131}$ Risk factors for PPHN include cesarean delivery, maternal African American or Asian race, high maternal pregravid body mass index $\left(>27 \mathrm{~kg} / \mathrm{m}^{2}\right)$, maternal diabetes mellitus, maternal asthma, maternal smoking, neonatal sepsis, meconium aspiration, and gestational age $34-37$ weeks and $>41$ weeks. ${ }^{132}$

A potential association between late-pregnancy exposure to fluoxetine and PPHN was initially reported in a small prospective cohort study of 228 exposed pregnancies and 254 control pregnancies with no antenatal fluoxetine exposure. ${ }^{86}$ An increased risk of PPHN was observed with late- versus first trimester fluoxetine exposure $(2.7 \%$ versus $0 \%)$. A subsequent multicenter case-control study by Chambers et al involving 377 women whose infants had PPHN and 836 matched control mother-infant pairs found a sixfoldincreased risk of PPHN with in utero SSRI exposure after 20 weeks' gestation (adjusted OR 6.1, 95\% CI 2.2-16.8). ${ }^{101}$ Neither SSRI exposure prior to the 20th gestational week nor exposure to non-SSRI antidepressants at any point during pregnancy was associated with increased risk of PPHN. The first of two retrospective analyses of Swedish Medical Birth Register data found an association between maternal SSRI use during the early stages of pregnancy and PPHN (relative risk [RR] 2.4, 95\% CI 1.2-4.3) after adjusting for maternal age, first parity, maternal body mass index, and smoking. ${ }^{133}$ A more recent analysis of that data included antenatal exposures to SSRIs and non-SSRI antidepressants, and showed an increase in the risk of PPHN associated with antidepressant use in both early (RR 2.30, 95\% CI 1.29-3.80) and later stages of pregnancy (RR 2.30, 95\% CI 1.17-4.85). ${ }^{94}$

The FDA responded to the initial positive report by issuing a public health advisory in 2006 about an increased risk of PPHN associated with maternal SSRI use after the 20th gestational week. ${ }^{134}$ However, subsequent results of a retrospective cohort study of 1,104 infants exposed to antidepressants during the third trimester ${ }^{135}$ and a retrospective chart review of 24,214 deliveries ( 808 of which involved antepartum SSRI exposure $)^{96}$ did not find an association between antenatal SSRI exposure and PPHN. In a large case-control study of 11,923 births (20 with primary PPHN), cesarean delivery prior to the onset of labor, but not in utero SSRI exposure after 20 weeks' gestation, was significantly associated with PPHN. ${ }^{136}$ The largest study to date based on health registry data from five Scandinavian countries (1,618,255 singleton births) identified 33 PPHN cases among 11,014 late-pregnancy SSRI exposures, or approximately three per 1,000 infants, compared with the background 
PPHN rate of one to two per 1,000 births (adjusted OR 2.1, $95 \%$ CI $1.5-3.0){ }^{137}$

In sum, it is unclear if late SSRI exposure increases the risk of PPHN, a rare but potentially serious adverse neonatal outcome. Results of positive studies have indicated an approximate two- to 2.5-fold increased risk of PPHN; however, the absolute risk appears to be very small, and the potential association between in utero antidepressants and PPHN remains controversial. If causal, the absolute risk has been estimated as three to 12 affected newborns per 1,000. ${ }^{101,137}$ Based in part on negative findings from more recent studies, the FDA has revised its original position, concluding that it is premature to reach definitive conclusions regarding the risk of PPHN with SSRI use in pregnancy. ${ }^{138}$

\section{Poor neonatal adaptation syndrome}

The term "poor neonatal adaptation syndrome" (PNAS) refers to a constellation of behaviors and clinical signs observed in neonates (irritability, agitation, tremors, jitteriness, shivering, increased muscular tone, digestive disturbances or feeding difficulties, and respiratory distress) that has been linked with late-third trimester exposure to SSRIs and other antidepressants. PNAS is transient and generally mild in severity, requiring supportive care only. More severe cases may require that initial recovery take place in a neonatal intensive care unit. ${ }^{139,140}$ The pathophysiology of PNAS is thought to involve either a serotonergic rebound effect (analogous to discontinuation syndromes observed in adults who undergo abrupt withdrawal of serotonergic antidepressants) or direct serotonergic toxicity. ${ }^{140,141}$

An early description of PNAS was provided by Chambers et al, who observed increased rates of neonatal respiratory problems, cyanosis with feeding, jitteriness, and special care nursery admission associated with third trimester exposure to fluoxetine. ${ }^{86}$ Oberlander et al reported on the incidence of transient neonatal complications associated with second and third trimester exposure to SSRIs, with or without concomitant antenatal exposure to benzodiazepine or clonazepam, among 46 exposed and 23 unexposed newborns. ${ }^{142}$ Transient irritability, jitteriness, hypothermia, sleep disruption, increased muscle tone, hypothermia, and initial lack of crying were observed in nearly $30 \%$ of exposed neonates. Others have provided evidence of PNAS associated with antenatal use of TCAs and SNRIs. ${ }^{97,133,143-147}$ Overall, the risk of PNAS appears to be similar between late pregnancy exposure to TCA, SNRIs, and SSRIs. ${ }^{148,149}$

A meta-analysis ${ }^{150}$ of prospective studies that examined adverse fetal and neonatal effects associated with antenatal antidepressant exposure (totaling 1,066 mother-infant pairs) showed a trend-level association in the primary analysis between third trimester SSRI exposure and PNAS that became significant after including results of a large study ${ }^{151}$ that included infants with in utero SSRI exposure during the first and third trimesters (OR 1.99, 95\% CI 1.43-2.77). A more recent meta-analysis of 12 studies (3,780 exposed infants) showed significantly increased risk of PNAS (OR 5.07, 95\% CI 3.25-7.90), infant respiratory distress (OR 2.20, 95\% CI 1.81-2.66), and tremors (OR 7.89, 95\% CI $3.33-18.73){ }^{152}$

Although not all studies are in agreement, ${ }^{153,154}$ the published literature appears to be more consistent with regard to a statistically and clinically significant association between antenatal antidepressant exposure during late pregnancy and the risk of PNAS, which may occur in $10 \%-30 \%$ of neonates with third trimester exposure to SSRIs or SNRIs. ${ }^{155,156}$ To limit the risk of PNAS occurrence, the FDA issued a recommendation in 2004 that health care providers consider tapering antidepressants used during the third trimester. ${ }^{157}$ However, the effectiveness of this practice for reducing the risk of PNAS has not been established in controlled studies. One population-based study of 119,547 birth records that compared the risk of adverse neonatal outcomes according to fetal antidepressant-exposure status during the last 14 days of pregnancy showed no difference in the risk of developing clinical signs of PNAS between infants in the exposed group and propensity score-matched controls. ${ }^{158}$ Further research is needed in order to determine whether suspension of effective antidepressant treatment during the late-third trimester reduces the risk of PNAS without increasing the risk of maternal depressive relapse, particularly during the postpartum period.

\section{Adverse obstetric outcomes}

\section{Premature delivery}

Premature delivery refers in general terms to the birth of an infant at $<37$ weeks gestational age, although prematurity can also refer to the birth of an infant before vital organs have developed sufficiently to allow postnatal survival. It is often used synonymously with a related term, preterm delivery (which refers only to delivery prior to 37 weeks' gestation), and occasionally with early preterm delivery (eg, delivery prior to 34 weeks' gestation). Regardless, decreased gestational age at delivery has been associated with increased neonatal morbidity and mortality compared with term-born children. ${ }^{159,160}$ One meta-analysis of 15 studies estimated the effects on antenatal antidepressant use on gestational age at 
delivery, and found a small but statistically significant difference between antidepressant-exposed and -unexposed babies (standardized mean difference [SMD] $-0.23,95 \%$ CI -0.34 to -0.12$)$. ${ }^{161}$ As referenced by the authors, this equates clinically with a difference in gestational age of 2-3 days.

With regard to premature delivery as a discrete outcome, observational studies have documented an increased risk associated with antenatal antidepressant exposure. ${ }^{87,162-165}$ However, not all studies are in agreement,,$^{89,90,92,100,166,167}$ and one study even documented a reduced risk of spontaneous preterm birth associated with medication treatment of depressive symptoms during pregnancy, although the main exposure group included both sedative medications and antidepressants. ${ }^{32}$ Most studies to date have focused on antenatal SSRI use; however, an increased risk of preterm delivery has also been reported for TCAs, venlafaxine, and mirtazapine. ${ }^{97,127,128}$

Whether or not an association between maternal antidepressant exposure and the risk of premature delivery is causal or confounded by underlying maternal depression has also been investigated, and is an ongoing focus of clinical debate. ${ }^{168,169}$ A prospective cohort study documented a higher risk of preterm delivery with continuous exposure to SSRIs or maternal depression across gestation compared with partial or no exposure. ${ }^{51}$ Another prospective study found significantly higher rates of premature delivery and special care nursery admissions in infants born to women with antenatal depression treated with antidepressants (predominantly SSRIs) compared with antenatally depressed women with no antidepressant or only limited antidepressant use and nondepressed controls. ${ }^{170}$ An inverse relationship between antidepressant dose and gestational age at delivery was observed. A very recent cohort study of 2,793 pregnant women documented an increased risk of preterm birth associated with SSRIs with or without a major depressive episode, while no increase in risk was observed for major depressive episode without SSRI use. ${ }^{171}$ Moreover, a recent meta-analysis of 14 studies found an increased risk of preterm delivery associated with maternal antidepressant use during pregnancy (pooled OR 1.55, 95\% CI 1.38-1.74). ${ }^{161}$ Comparisons of depressed mothers with and without antidepressant exposure (five studies) showed a trend-level association with similar effect size as that of the main analysis (pooled OR $1.58,95 \% \mathrm{CI}$ 0.97-2.56), suggesting that the effect of antenatal antidepressant exposure on the risk of premature delivery may be independent of maternal depression. Others, however, have documented significantly higher rates of preterm delivery with antenatal SSRI exposure that attenuated after controlling for factors that may serve as proxy indicators of maternal depression severity and psychiatric comorbidity. ${ }^{6,171}$

In summary, there is evidence of an increased incidence of preterm delivery associated with maternal antidepressant use in some studies and a greater risk of preterm delivery in the most recent meta-analysis addressing this topic, but it is still unclear whether maternal antidepressant use increases the risk of premature delivery independently of other factors. Maternal depression severity and psychiatric comorbidity may serve as important sources of confounding in existing studies.

\section{Spontaneous abortion}

Spontaneous abortion refers to the loss of a fetus prior to the 20th gestational week in the absence of an elective termination of pregnancy or other outside intervention. Spontaneous abortion is thought to occur in $12 \%-15 \%$ of diagnosed pregnancies, ${ }^{172}$ with higher rates (approaching 40\%) in pregnant women over the age of 40 years. ${ }^{172}$ Chromosomal abnormalities are the leading cause of spontaneous abortions, while thrombotic events leading to inadequate fetal blood supply and adverse maternal health factors are less common causes. ${ }^{172,173}$ Spontaneous abortion has been linked with both maternal depression ${ }^{174}$ and maternal use of various antidepressants during pregnancy, including SSRIs, venlafaxine, and other agents..$^{90,103,120,127,174-178}$ Other findings from mainly small prospective cohort studies have been negative. ${ }^{86,89,179,180}$

Three meta-analyses document small increases in the risk of spontaneous abortion associated with maternal antidepressant use during pregnancy. Hemels et al conducted a meta-analysis of six homogeneous cohort studies $(1,534$ exposed pregnancies) and reported a pooled RR of 1.45 $(95 \%$ CI $1.19-1.77)$ and an increase in risk of $3.9 \%$ (95\% CI $1.9 \%-6.0 \%)$ among antidepressant-exposed pregnancies versus matched control pregnancies. ${ }^{174} \mathrm{~A}$ subsequent metaanalysis of nine nonheterogeneous studies (five of which reported on rates of spontaneous abortion in 1,900 exposed pregnancies) by Rahimi et al reported a summary OR of 1.7 (95\% CI 1.28-2.24). ${ }^{109}$ The majority of reviewed studies did not adequately address important confounding factors, including history of miscarriage, rates of induced abortion, maternal age, and severity of maternal depression. ${ }^{126,181}$ The most recent meta-analysis by Ross et al included three studies that met prespecified quality-assessment criteria (1,503 exposed pregnancies), and generally supported the conclusions of earlier meta-analyses by reporting a pooled OR of 1.47 (95\% CI 0.99-2.17). ${ }^{161}$ Comparison with a 
depressed but antidepressant-unexposed control group was not possible, owing to a lack of data.

Not included in the meta-analyses was a very recent population-based retrospective cohort study using data from all identified pregnancies in Denmark (1997-2008), 22,061 of which involved evidence of antenatal antidepressant use and 1,843 of which included a diagnosis of depression but no evidence of antenatal antidepressant use. ${ }^{182}$ A total of $2,637(12.0 \%)$ cases in the antidepressant-exposed group and $1,843(11.4 \%)$ in the depressed but nonexposed group ended in spontaneous abortion (RR 1.14, 95\% CI 1.10-1.18). However, after restricting the analysis to women with a registry-based diagnosis of depression, the adjusted RR for spontaneous abortion with antenatal antidepressant exposure was 1.00 (95\% CI 0.80-1.24). No individual SSRIs were associated with spontaneous abortions; however, venlafaxine (RR 1.80, 95\% CI 1.19-2.72), duloxetine (RR 3.12, 95\% CI 1.55-6.31) and mirtazapine (RR 2.23, 95\% CI 1.34-3.70) were associated with an increased risk of spontaneous abortion.

In sum, available studies suggest that antenatal antidepressant use (including SSRIs) may be associated with a small but statistically significant increase in the risk of spontaneous abortion. However, conclusions from available studies are contradictory, and the validity of the small effect sizes documented in meta-analyses and most individual studies are threatened by possible confounding. Many studies did not adequately control for important risk factors for spontaneous abortion, including history of miscarriage, maternal age, maternal smoking status, severity of maternal depression, concomitant psychiatric disorders (including substance-use disorders), other diagnoses for which antidepressants may be prescribed, and maternal use of other medications that may also elevate the risk of spontaneous abortion. ${ }^{126}$ The larger risk estimates documented for some non-SSRI antidepressants ${ }^{176,178,182}$ may reflect greater severity of underlying depression, since these agents are not generally considered immediate first-line therapeutic options. Moreover, many studies did not clearly distinguish between spontaneous and induced abortions, ${ }^{161,181}$ which could have resulted in biased estimates of spontaneous abortion risk with antidepressant use, given that maternal depression itself may increase the risk of elective termination of pregnancy. ${ }^{183,184}$

\section{Poor infant growth and low birth weight}

Several observational studies have documented small increases in the risk of low birth weight for gestational age with maternal antidepressant use during pregnancy. $6,86,100,151,162,164,185$
Others have documented linear decreases in gestational age associated with higher antidepressant doses used during pregnancy, ${ }^{170}$ or increased risk of low birth weight associated with high doses of fluoxetine taken throughout pregnancy. ${ }^{102}$ However, the majority of individual published studies have been negative, ${ }^{51,90,100,127,153,175,179,186-192}$ and one study documented a possible increase in the risk of large birth weight with the use of TCAs early in pregnancy. ${ }^{87}$

Underlying maternal depression and anxiety disorders have also been associated with poor infant growth and low birth weight, ${ }^{6,30,31,33-37}$ raising the possibility that the relationship between maternal antidepressant use during pregnancy and the risk of low birth weight or poor fetal growth may be confounded by antidepressant indication. However, few studies accounted for maternal depression diagnosis or depression severity, or risk factors for low birth weight that may correlate significantly with maternal depression, such as smoking, alcohol use, and suboptimal maternal weight gain during pregnancy. ${ }^{17,126,193-195}$ Even for studies that did account, at least partially, for these factors, results are mixed. For example, in one prospective cohort study of 174 pregnant women (46 of whom took an SSRI during pregnancy, 31 of whom were diagnosed with major depression but did not take an SSRI during pregnancy, and 97 of whom were exposed to neither depression nor an SSRI during pregnancy), no significant associations between antenatal SSRI exposure or antenatal depression and infant weight, head circumference, or length were observed compared with no antenatal exposure to SSRIs or depression. ${ }^{196}$ By contrast, a small casecontrol study of 27 pregnant women who took antidepressant medications for diagnosed major depression and 27 matched controls with depression severity assessed using the Beck Depression Inventory (second edition) ${ }^{197}$ showed an increased risk of low birth weight (OR 8.33, 95\% CI 1.11-62.67) and significantly lower postpartum body weight, length, and head circumference measured at 1 month postdelivery with antenatal antidepressant exposure. ${ }^{165}$ There was no significant association between depressive symptoms, smoking, or alcohol use and risk of low birth weight or subsequent infant-growth measures, suggesting an independent effect of medication exposure.

A recent meta-analysis of 20 studies (over 5,000 exposed pregnancies) with moderate heterogeneity reported a small SMD in birth weight between infants with in utero antidepressant exposure and those with no such exposure (SMD -0.10 , $95 \% \mathrm{CI}-0.16$ to -0.03$)$, corresponding to a difference of $-74 \mathrm{~g}$ (95\% CI -117 to $-31 \mathrm{~g}) .{ }^{161}$ After restricting the control group to infants born to depressed mothers with no antidepressant 
exposure, the SMD in birth weight was nearly zero and not statistically significant (SMD $-0.02,95 \% \mathrm{CI}-0.10$ to 0.06 ).

In sum, maternal antidepressant use during pregnancy may be associated with small decreases in birth weight, but maternal depression may mediate this relationship. Furthermore, data from the most recent meta-analysis suggest that the average difference in birth weight between antidepressant-exposed and -unexposed babies is approximately $74 \mathrm{~g}$, or $\sim 0.16 \mathrm{lb} .^{161}$ The clinical significance of such a small difference in birth weight may be questionable, especially for birth weights that still fall within the normal range.

\section{Preeclampsia}

Gestational hypertension (blood pressure $\geq 140 / 90 \mathrm{mmHg}$ on at least two separate readings spaced $\geq 6$ hours apart after 20 weeks' gestation occurring in women who were normotensive before pregnancy) and preeclampsia (gestational hypertension accompanied by proteinuria) collectively refer to a spectrum of hypertensive conditions that develop during pregnancy, with or without accompanying organ dysfunction. ${ }^{198}$ Approximately half of gestational hypertension cases that develop prior to 30 weeks' gestation will progress to preeclampsia. ${ }^{198}$ Maternal and perinatal outcomes related to mild gestational hypertension and preeclampsia are similar to those of normotensive pregnancies. ${ }^{199}$ Severe gestational hypertension, on the other hand, is associated with higher rates of cesarean delivery, placental abruption, and preterm delivery, while severe preeclampsia is associated with greater risk of perinatal mortality, placental abruption, and severe maternal morbidity and mortality compared with unaffected pregnancies. ${ }^{200,201}$ Risk factors for gestational hypertension and preeclampsia include advanced maternal age, nulliparity, history of hypertension or renal disease, obesity, family or personal history of preeclampsia, multifetal gestation, and history of diabetes. ${ }^{198}$ More recently, maternal depression and anxiety disorders ${ }^{202,203}$ and greater depression severity ${ }^{204}$ have been shown to increase the risk of developing preeclampsia, independently of the effects of maternal age, race, and pregravid body mass index.

A potential link between maternal antidepressant use during pregnancy and gestational hypertension, preeclampsia, or the two combined has been suggested. A cohort study by Qiu et al of pregnant women with a mood or anxiety disorder diagnosis showed a modest but not statistically significant increase in the risk of gestational hypertension associated with maternal use of SSRIs (OR 1.81, 95\% CI 0.69-4.75) and SSRIs with adjunctive non-SSRI psychotropic medications (mainly TCAs and benzodiazepines, OR 2.88,
95\% CI 0.40-20.98). ${ }^{202}$ However, this study had low statistical power, and was not designed to investigate the effect of antidepressants on the risk of preeclampsia. Retrospective studies using much-larger cohorts have reported significant associations between maternal antidepressant use during pregnancy and the risk of gestational hypertension and/ or preeclampsia. ${ }^{94,205}$ One nested case-control study that focused on the risk of gestational hypertension associated with use of antidepressants during pregnancy documented a significant increase in risk associated with general use of antidepressants (OR 1.52, 95\% CI 1.10-2.09) and with SSRIs (OR 1.53, 95\% CI 1.01-2.33) and paroxetine (OR 1.81, 95\% CI 1.02-3.23) in stratified analyses. ${ }^{206} \mathrm{~A}$ large retrospective cohort study of 69,448 pregnancies in women with insurance claim-based diagnoses of depression found increased risk of preeclampsia associated with SSRI (RR 1.22, 95\% CI 0.97-1.54), SNRI (RR 1.95, 95\% CI 1.25-3.03), and TCA monotherapy (RR 3.23, 95\% CI 1.87-5.59) compared with no antidepressant use. ${ }^{207}$ Similar findings were reported in comparisons between cohort members with evidence of continuous antidepressant use during pregnancy and those with evidence of antidepressant discontinuation during gestational weeks 10-24 or beyond.

In summary, available evidence suggests that pregnant women treated with antidepressants are at higher risk for gestational hypertension and preeclampsia. This includes evidence of a possible effect independent of underlying maternal depression or anxiety disorder diagnoses; however, existing studies do not address confounding by depression severity. On the one hand, findings of increasing risk of preeclampsia with SNRIs and TCAs may not be that surprising, since the choice to use these medications over first-line treatments in pregnancy may reflect greater symptom burden and treatment resistance. These findings are noteworthy, given the risk of blood pressure increases that can occur during treatment with SNRIs and selected TCAs. ${ }^{208-210}$ Importantly, it is still unclear if antenatal antidepressant exposure is associated with severe (rather than mild) gestational hypertension or preeclampsia specifically.

\section{Neurodevelopmental and behavioral outcomes}

Several studies have examined the risk of impaired longterm neurobehavioral and cognitive development in children exposed in utero to antidepressants. Most studies have focused on the potential effects of SSRIs and SNRIs. In general, the majority of reports are from small prospective cohort studies that have shown no significant effect of maternal antenatal 
antidepressant use on global IQ, temperament, or language, motor, or behavioral development in offspring. ${ }^{43,186,189,211,212}$ Two prospective studies showed that poor neonatal adaptation associated with antidepressant exposure in utero was not associated with subsequent developmental impairments. ${ }^{44,142}$ In two of the reviewed studies, maternal depression, maternal depression severity during pregnancy, and the number of depressive episodes after delivery were identified as risk factors for poorer behavioral, cognitive, and language development in offspring. ${ }^{43,44}$ Follow-up studies of TCA-exposed babies have also shown normal motor, behavioral, and cognitive development. ${ }^{43,144,189}$

On the other hand, Casper et al reported a significantly higher prevalence of subtle problems with motor development and control and lower Apgar scores in offspring (up to 40 months of age) of depressed mothers who received SSRI treatment during pregnancy (31 exposed pregnancies) compared with babies of mothers diagnosed with major depression not treated with medications during pregnancy. ${ }^{153}$ Alcohol consumption was reported more frequently among the exposed pregnancies. An analysis of data from the Danish National Birth Cohort that included 415 pregnancies with second or third trimester antidepressant use and 489 pregnancies with maternal depression but no antidepressant use showed delayed motor development in offspring from exposed pregnancies as assessed by telephone interview, although time required to sit and walk still fell within the normal range of development. ${ }^{213}$ Children of antidepressant-treated mothers were at significantly higher risk of not being able to sit without support at 6 months of age (OR 2.1, 95\% CI 1.23-3.60) or occupy themselves at 19 months of age (OR 2.1, 95\% CI 1.09-4.02). Neither study was able to evaluate the effects of individual medications. Finally, a meta-analysis of observational studies reporting the effects of maternal antidepressant use on 1-minute (ten studies) and 5-minute Apgar scores (14 studies) found small but statistically significant differences between antidepressant-exposed and -unexposed babies at 1 minute (SMD - 0.19, 95\% CI -0.30 to -0.08) and 5 minutes (SMD $-0.33,95 \% \mathrm{CI}-0.47$ to -0.20$).{ }^{161}$ As pointed out by the authors, this equates clinically with a difference in Apgar score of about 0.5 point at each time point.

In summary, relatively few studies have been conducted that focus on the effects of in utero antidepressant exposure on neurobehavioral, cognitive, and motor development. Most studies focused on such outcomes shortly after delivery or during early childhood. Few data are available regarding whether or not these outcomes related to cognitive or behavioral functioning persist later in life. ${ }^{214}$ Many studies did not adequately control for the potential effects of maternal IQ, socioeconomic status, fetal exposure to alcohol and nicotine, duration and severity of maternal depression, and other concomitant fetal medication exposures that can also impact brain development. Data on the effects of individual antidepressant medications are also lacking. Further studies are needed to assess the independent effects of individual antidepressant medications on both early and later childhood neurobehavioral, cognitive, and motor development.

\section{Summary and practical implications}

Clinicians who treat women with antenatal depression are fortunate to have a large number of pharmacological and nonpharmacological therapeutic tools at their disposal. In spite of the wide range of treatment options and increasing recognition of the adverse effects of untreated or undertreated antenatal depression, rates of psychiatric treatment among pregnant and postpartum women with mood disorders, including major depression, are very low. ${ }^{215}$ Even when women are appropriately screened, research suggests that more than $80 \%$ of women with antenatal depression do not receive treatment. ${ }^{5}$ This is particularly troubling in view of the accumulating evidence suggesting that successful treatment of maternal depression leads to better outcomes for both mothers and their children, particularly if remission of

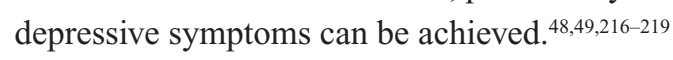

It is important to recognize that several pragmatic challenges make treating antenatal depression very difficult. First, there is little information about the comparative effectiveness of many of the most commonly employed therapeutic modalities for treating major depression in pregnant women, and many patients who receive treatment with psychotherapy or antidepressant medications - whether pregnant or not do not benefit, or experience only modest improvement in depressive symptoms and functioning. The pregnancy and developing fetus are therefore still exposed to the potentially harmful effects of residual depressive symptoms in many cases, and we are not yet able to predict with acceptable certainty which pregnant women are more likely to benefit from a given set of treatments.

Second, particularly with respect to the potential harms associated with treating antenatal depression with antidepressants, a great deal of experience and skill is required to interpret a conflicting and in some cases controversial medical literature made up almost entirely of observational studies with increasingly complex designs and statistical approaches. The complex designs and statistical approaches are needed to reduce, or at least limit to the greatest extent possible, the effects of confound- 
ing and bias inherent in nonrandomized studies. However, they also make studies more difficult to interpret, and most clinicians lack the advanced methodological training to do so. Because observational studies cannot firmly establish causal links between antidepressant use during pregnancy and adverse obstetric or fetal outcomes, no single study can be regarded as definitive. This does not mean that observational studies cannot yield data of sufficient quality to inform clinical practice. Arguments in favor of causality can be made with consistent replication of findings across numerous studies from different populations. However, this does mean that clinicians must invest considerable effort to familiarize themselves with the large volume of existing literature and stay up to date with the newest published data. The increasing time demands and rigors of daily practice erode and work against many clinicians' ability to maintain this capability.

In spite of these challenges, we believe existing literature and clinical practice guidelines do provide useful guidance. ${ }^{16}$ First, it is helpful to remember that although this review is focused on major depression, not all antenatal depression is major depressive disorder. Depressive symptoms characterize a large number of conditions that can arise during pregnancy, ranging from nonspecific reactions to stressors to major affective syndromes, including major depression and bipolar (type I or II) depression. This is not to say that other forms of maternal depression are unimportant; indeed, other depressive states and even high levels of maternal stress during pregnancy can adversely affect fetal and birth outcomes, ${ }^{220}$ and many physical symptoms overlap between major depression and pregnancy, such as fatigue, sleep disruption, weight change, and concentration difficulties. ${ }^{221}$ Although treatment for nonspecific or poorly characterized depressive states may be required to protect against their potential adverse effects, there is currently little or no high-quality evidence supporting the use of antidepressants or other therapies for nonspecific or poorly characterized depressive states. On the other hand, the use of antidepressants and/or structured psychotherapies for patients with a firm diagnosis of major depression in general and severe major depression in particular is clearly supported.

In addition to establishing the diagnosis of major depression, factors that bear on treatment selection and likelihood of antepartum depression relapses (for those with existing diagnoses of major depression) must also be assessed. Assessment of the former includes, at minimum, evaluation of current depressive symptom severity and impact on daily functioning, history of treatment(s) and treatment response, availability of treatment resources, medical and obstetric history, and patient preference. ${ }^{220}$ Additional factors that drive treatment selection include duration, recurrence, and severity of depressive symptoms during past depressive episodes; history of self-harm tendencies; comorbid psychiatric and substance-use disorders (including alcohol, drugs of abuse, and tobacco: currently, during periods of active depression treatment, and when not receiving treatment); quality and availability of social supports; family history of major depression and treatment response; family situation; and evidence of domestic abuse or violence. Risk factors for depressive relapse during pregnancy include longer illness duration, history of recurrent illness, history of suicidality, family history of depressive illness, lack of social support, comorbid anxiety disorders, existing or impending single parenthood, low socioeconomic status, unintended pregnancy, exposure to domestic violence, and ongoing stressful life events. ${ }^{50,221}$

Because maternal major depression can respond positively to pharmacotherapy, psychotherapy, and other interventions, and because no single intervention is uniformly successful or devoid of risk, it is perhaps ideal for clinicians to avoid the "simple" choice of whether or not to treat antenatal depression with antidepressants in favor of beginning with a broad list of reasonable therapeutic options. Such a list can be generated by considering what treatments would have the highest chance of achieving remission in an individual patient, given a thorough assessment of the factors listed earlier. This may include nonpharmacological treatments only, antidepressant medication only, or a combination of these. As such, the initial list may be quite large, particularly for patients with limited treatment histories. Each option can be discussed with the patient and support system, mindful that there are no guarantees of positive outcome. The initial list of options can then be narrowed based on relative obstetric and fetal safety of each available service, clinical factors, and individual patient values and concerns. Fully informed decision making requires that the risks of both untreated maternal depression and the risks associated with each proposed intervention be reviewed, and that all reasonable treatment options be discussed.

\section{Disclosure}

The authors report no conflicts of interest in this work. In the past, Dr Bobo has received grants/research support from Cephalon and has served on speaker panels for Janssen Pharmaceutica and Pfizer.

\section{References}

1. Kessler RC, Berglund P, Demler O, et al. The epidemiology of major depressive disorder: results from the National Comorbidity Survey Replication (NCS-R). JAMA. 2003;289:3095-3105. 
2. Burt VK. Epidemiology of depression throughout the female life cycle. J Clin Psychiatry. 2002;63:9-15.

3. Burke KC, Burke JD, Rae DS, Regirer DA. Comparing age at onset of major depression and other psychiatric disorders by birth cohorts in five US community populations. Arch Gen Psychiatry. 1991;48:789-795.

4. Gavin NI, Gaynes BN, Lohr KN, Meltzer-Brody S, Gartlehner G, Swinson T. Perinatal depression: a systematic review of prevalence and incidence. Obstet Gynecol. 2005;106:1071-1083.

5. Marcus SM, Flynn HA, Blow FC, Barry KL. Depressive symptoms among pregnant women screened in obstetrics settings. $J$ Womens Health (Larchmt). 2003;12:373-380.

6. Oberlander TF, Warburton W, Misri S, Aghajanian J, Hertzman C. Neonatal outcomes after prenatal exposure to selective serotonin reuptake inhibitor antidepressants and maternal depression using population-based linked health data. Arch Gen Psychiatry. 2006;63: 898-906.

7. Bennett HA, Einarson A, Koren G, Einarson TR. Prevalence of depression during pregnancy: systematic review. Obstet Gynecol. 2004;103: 698-709.

8. Nutt DJ, Davidson JR, Gelenberg AJ, et al. International consensus statement on major depressive disorder. J Clin Psychiatry. 2010; 71 Suppl E1:e08.

9. Cooper WO, Willy ME, Pont SJ, Ray WA. Increasing use of antidepressants in pregnancy. Am J Obstet Gynecol. 2007;196:544-545.

10. Andrade SE, Raebel MA, Brown J, et al. Use of antidepressant medications during pregnancy: a multisite study. Am J Obstet Gynecol. 2008;198:194-195.

11. Ramos E, Oraichi D, Rey E, Blais L, Bérard A. Prevalence and predictors of antidepressant use in a cohort of pregnant women. BJOG. 2007;114:1055-1064.

12. Ververs T, Kaasenbrood H, Visser G, Schobben F, de Jong-van den Berg L, Egberts T. Prevalence and patterns of antidepressant drug use during pregnancy. Eur J Clin Pharmacol. 2006;62:863-870.

13. Bakker MK, Kölling P, van den Berg PB, de Walle HE, de Jong van den Berg LT. Increase in use of selective serotonin reuptake inhibitors in pregnancy during the last decade, a population-based cohort study from The Netherlands. Br J Clin Pharmacol. 2008;65:600-606.

14. Kuehn BM. No easy answers for physicians caring for pregnant women with depression. JAMA. 2009;302:2413-2414, 2420.

15. Wisner KL, Appelbaum PS, Uhl K, Goldkind SF. Pharmacotherapy for depressed pregnant women: overcoming obstacles to gathering essential data. Clin Pharmacol Ther. 2009;86:362-365.

16. Yonkers KA, Wisner KL, Stewart DE, et al. The management of depression during pregnancy: a report from the American Psychiatric Association and the American College of Obstetricians and Gynecologists. Obstet Gynecol. 2009;114:703-713.

17. Zuckerman B, Amaro H, Bauchner H, Cabral H. Depressive symptoms during pregnancy: relationship to poor health behaviors. Am J Obstet Gynecol. 1989;160:1107-1111.

18. Perkin MR, Bland JM, Peacock JL, Anderson HR. The effect of anxiety and depression during pregnancy on obstetric complications. Br JObstet Gynaecol. 1993;100:629-634.

19. Pritchard CW. Depression and smoking in pregnancy in Scotland. J Epidemiol Community Health. 1994;48:377-382.

20. Ikard FF, Tomkins S. The experience of affect as a determinant of smoking behavior: a series of validity studies. J Abnorm Psychol. 1973;81: $172-181$.

21. Orr ST, Blazer DG, James SA, Reiter JP. Depressive symptoms and indicators of maternal health status during pregnancy. JWomens Health (Larchmt). 2007;16:535-542.

22. Stowe ZN, Hostetter AL, Newport DJ. The onset of postpartum depression: implications for clinical screening in obstetrical and primary care. Am J Obstet Gynecol. 2005;192:522-526.

23. Nulman I, Koren G, Rovet J, et al. Neurodevelopment of children following prenatal exposure to venlafaxine, selective serotonin reuptake inhibitors, or untreated maternal depression. Am J Psychiatry. 2012;169: $1165-1174$.
24. Lindahl V, Pearson JL, Colpe L. Prevalence of suicidality during pregnancy and the postpartum. Arch Womens Ment Health. 2005;8: 77-87.

25. Pearlstein T. Perinatal depression: treatment options and dilemmas. J Psychiatry Neurosci. 2008;33:302-318.

26. Vintzileos A, Ananth CV, Smulian JC, Scorza WE, Knuppel RA. The impact of prenatal care on postneonatal deaths in the presence and absence of antenatal high-risk conditions. Am J Obstet Gynecol. 2002;187:1258-1262.

27. Kelly RH, Danielsen BH, Golding JM, Anders TF, Gilbert WM, Zatzick DF. Adequacy of prenatal care among women with psychiatric diagnoses giving birth in California in 1994 and 1995. Psychiatr Serv. 1999;50:1584-1590.

28. Kim DR, Sockol LE, Sammel MD, Kelly C, Moseley M, Epperson CN. Elevated risk of adverse obstetric outcomes in pregnant women with depression. Arch Womens Ment Health. 2013;16:475-482.

29. Mulder EJ, Robles de Medina PG, Huizink AC, Van den Bergh BR, Buitelaar JK, Visser GH. Prenatal maternal stress: effects on pregnancy and the (unborn) child. Early Hum Dev. 2002;70:3-14.

30. Grote NK, Bridge JA, Gavin AR, Melville JL, Iyengar S, Katon WJ. A meta-analysis of depression during pregnancy and the risk of preterm birth, low birth weight, and intrauterine growth restriction. Arch Gen Psychiatry. 2010;67:1012-1024.

31. Steer RA, Scholl TO, Hediger ML, Fischer RL. Self-reported depression and negative pregnancy outcomes. J Clin Epidemiol. 1992;45: 1093-1099.

32. Dayan J, Creveuil C, Marks MN, et al. Prenatal depression, prenatal anxiety, and spontaneous preterm birth: a prospective cohort study among women with early and regular care. Psychosom Med. 2006;68: 938-946.

33. Diego MA, Field T, Hernandez-Reif M, Schanberg S, Kuhn C, Gonzalez-Quintero VH. Prenatal depression restricts fetal growth. Early Hum Dev. 2009;85:65-70.

34. Rahman A, Iqbal Z, Bunn J, Lovel H, Harrington R. Impact of maternal depression on infant nutritional status and illness: a cohort study. Arch Gen Psychiatry. 2004;61:946-952.

35. Uguz F, Gezginc K, Yazici F. Are major depression and generalized anxiety disorder associated with intrauterine growth restriction in pregnant women? A case-control study. Gen Hosp Psychiatry. 2011;33: 640. e7-e9.

36. Paarlberg KM, Vingerhoets AJ, Passchier J, Dekker GA, Heinen AG, van Geijn HP. Psychosocial predictors of low birthweight: a prospective study. Br J Obstet Gynaecol. 1999;106:834-841.

37. Evans J, Heron J, Patel RR, Wiles N. Depressive symptoms during pregnancy and low birth weight at term. Br J Psychiatry. 2007;191: $84-85$.

38. Marcus SM. Depression during pregnancy: rates, risks and consequencesMotherisk Update 2008. Can J Clin Pharmacol. 2009;16:e15-e22.

39. Grigoriadis S, VonderPorten EH, Mamisashvili L, et al. The impact of maternal depression during pregnancy on perinatal outcomes: a systematic review and meta-analysis. J Clin Psychiatry. 2013;74: e321-e341.

40. McFarland J, Salisbury AL, Battle CL, Hawes K, Halloran K, Lester BM. Major depressive disorder during pregnancy and emotional attachment to the fetus. Arch Womens Ment Health. 2011;14:425-434.

41. Deave T, Heron J, Evans J, Emond A. The impact of maternal depression in pregnancy on early child development. BJOG. 2008;115: 1043-1051.

42. Paulson JF, Keefe HA, Leiferman JA. Early parental depression and child language development. J Child Psychol Psychiatry. 2009;50: 254-262.

43. Nulman I, Rovet J, Stewart DE, et al. Child development following exposure to tricyclic antidepressants or fluoxetine throughout fetal life: a prospective, controlled study. Am J Psychiatry. 2002;159:1889-1895.

44. Misri S, Reebye P, Kendrick K, et al. Internalizing behaviors in 4-year-old children exposed in utero to psychotropic medications. Am J Psychiatry. 2006;163:1026-1032. 
45. Murray L, Sinclair D, Cooper P, Ducournau P, Turner P, Stein A. The socioemotional development of 5-year-old children of postnatally depressed mothers. J Child Psychol Psychiatry. 1999;40:1259-1271.

46. Downey G, Coyne JC. Children of depressed parents: an integrative review. Psychol Bull. 1990;108:50-76.

47. Pilowsky DJ, Wickramaratne PJ, Rush AJ, et al. Children of currently depressed mothers: a STAR*D ancillary study. J Clin Psychiatry. 2006;67:126-136.

48. Weissman MM, Pilowsky DJ, Wickramaratne PJ, et al. Remissions in maternal depression and child psychopathology: a STAR*D-child report. JAMA. 2006;295:1389-1398.

49. Pilowsky DJ, Wickramaratne P, Talati A, et al. Children of depressed mothers 1 year after the initiation of maternal treatment: findings from the STAR*D-Child Study. Am J Psychiatry. 2008;165:1136-1147.

50. Cohen LS, Altshuler LL, Harlow BL, et al. Relapse of major depression during pregnancy in women who maintain or discontinue antidepressant treatment. JAMA. 2006;295:499-507.

51. Wisner KL, Sit DK, Hanusa BH, et al. Major depression and antidepressant treatment: impact on pregnancy and neonatal outcomes. Am J Psychiatry. 2009;166:557-566.

52. Yonkers KA, Gotman N, Smith MV, et al. Does antidepressant use attenuate the risk of a major depressive episode in pregnancy? Epidemiology. 2011;22:848-854.

53. Claridge AM. Efficacy of systemically oriented psychotherapies in the treatment of perinatal depression: a meta-analysis. Arch Womens Ment Health. 2014;17:3-15.

54. Sockol LE, Epperson CN, Barber JP. A meta-analysis of treatments for perinatal depression. Clin Psychol Rev. 2011;31:839-849.

55. Brandon AR, Ceccotti N, Hynan LS, Shivakumar G, Johnson N, Jarrett RB. Proof of concept: partner-assisted interpersonal psychotherapy for perinatal depression. Arch Womens Ment Health. 2012;15:469-480.

56. O’Mahen H, Himle JA, Fedock G, Henshaw E, Flynn H. A pilot randomized controlled trial of cognitive behavioral therapy for perinatal depression adapted for women with low incomes. Depress Anxiety. 2013;30:679-687.

57. Meager I, Milgrom J. Group treatment for postpartum depression: a pilot study. Aust N ZJ Psychiatry. 1996;30:852-860.

58. Appleby L, Warner R, Whitton A, Faragher B. A controlled study of fluoxetine and cognitive-behavioural counselling in the treatment of postnatal depression. BMJ. 1997;314:932-936.

59. Chabrol H, Teissedre F, Saint-Jean M, Teisseyre N, Roge B, Mullet E. Prevention and treatment of post-partum depression: a controlled randomized study on women at risk. Psychol Med. 2002;32: 1039-1047.

60. Glazier RH, Elgar FJ, Goel V, Holzapfel S. Stress, social support, and emotional distress in a community sample of pregnant women. J Psychosom Obstet Gynaecol. 2004;25:247-255.

61. St-André M. Psychotherapy during pregnancy: opportunities and challenges. Am J Psychother. 1993;47:572-590.

62. Nascimento SL, Surita FG, Cecatti JG. Physical exercise during pregnancy: a systematic review. Curr Opin Obstet Gynecol. 2012;24: 387-394.

63. Blumenthal JA, Babyak MA, Moore KA, et al. Effects of exercise training on older patients with major depression. Arch Intern Med. 1999;159:2349-2356.

64. Blumenthal JA, Babyak MA, Doraiswamy PM, et al. Exercise and pharmacotherapy in the treatment of major depressive disorder. Psychosom Med. 2007;69:587-596.

65. Babyak M, Blumenthal JA, Herman S, et al. Exercise treatment for major depression: maintenance of therapeutic benefit at 10 months. Psychosom Med. 2000;62:633-638.

66. Robledo-Colonia AF, Sandoval-Restrepo N, Mosquera-Valderrama YF, Escobar-Hurtado C, Ramírez-Vélez R. Aerobic exercise training during pregnancy reduces depressive symptoms in nulliparous women: a randomised trial. J Physiother. 2012;58:9-15.

67. Gaston A, Prapavessis H. Tired, moody and pregnant? Exercise may be the answer. Psychol Health. 2013;28:1353-1369.
68. Songøygard KM, Stafne SN, Evensen KA, Salvesen KA, Vik T, Mørkved S. Does exercise during pregnancy prevent postnatal depression? A randomized controlled trial. Acta Obstet Gynecol Scand. 2012;91:62-67.

69. Golden RN, Gaynes BN, Ekstrom RD, et al. The efficacy of light therapy in the treatment of mood disorders: a review and meta-analysis of the evidence. Am J Psychiatry. 2005;162:656-662.

70. Even C, Schroder CM, Friedman S, Rouillon F. Efficacy of light therapy in nonseasonal depression: a systematic review. J Affect Disord. 2008;108:11-23.

71. Oren DA, Wisner KL, Spinelli M, et al. An open trial of morning light therapy for treatment of antepartum depression. Am J Psychiatry. 2002;159:666-669.

72. Epperson CN, Terman M, Terman JS, et al. Randomized clinical trial of bright light therapy for antepartum depression: preliminary findings. $J$ Clin Psychiatry. 2004;65:421-425.

73. Wirz-Justice A, Bader A, Frisch U, et al. A randomized, double-blind, placebo-controlled study of light therapy for antepartum depression. J Clin Psychiatry. 2011;72:986-993.

74. Kim DR, Epperson N, Pare E, et al. An open label pilot study of transcranial magnetic stimulation for pregnant women with major depressive disorder. J Womens Health (Larchmt). 2011;20:255-261.

75. Hizlı Sayar G, Ozten E, Tufan E, et al. Transcranial magnetic stimulation during pregnancy. Arch Womens Ment Health. 2014;17:311-315.

76. Miller LJ. Use of electroconvulsive therapy during pregnancy. Hosp Community Psychiatry. 1994;45:444-450.

77. O'Reardon JP, Cristancho MA, von Andreae CV, Cristancho P, Weiss D. Acute and maintenance electroconvulsive therapy for treatment of severe major depression during the second and third trimesters of pregnancy with infant follow-up to 18 months: case report and review of the literature. J ECT. 2011;27:e23-e26.

78. Rabheru K. The use of electroconvulsive therapy in special patient populations. Can J Psychiatry. 2001;46:710-719.

79. Leiknes KA, Cooke MJ, Jarosch-von Schweder L, Harboe I, Hoie B. Electroconvulsive therapy during pregnancy: a systematic review of case studies. Arch Womens Ment Health. Epub November 24, 2013.

80. Dennis CL, Allen K. Interventions (other than pharmacological, psychosocial or psychological) for treating antenatal depression. Cochrane Database Syst Rev. 2008:CD006795.

81. Sado M, Ota E, Stickley A, Mori R. Hypnosis during pregnancy, childbirth, and the postnatal period for preventing postnatal depression. Cochrane Database Syst Rev. 2012;6:CD009062.

82. Manber R, Schnyer RN, Lyell D, et al. Acupuncture for depression during pregnancy: a randomized controlled trial. Obstet Gynecol. 2010;115:511-520.

83. Rynn L, Cragon J, Correa A. Update of overall prevalence of major birth defects - Atlanta, Georgia, 1978-2005. MMWR Morb Mortal Wkly Rep. 2008;57:1-5.

84. Finnell RH. Teratology: general considerations and principles. JAllergy Clin Immunol. 1999;103:S337-S342.

85. Malm H. Prenatal exposure to selective serotonin reuptake inhibitors and infant outcome. Ther Drug Monit. 2012;34:607-614.

86. Chambers CD, Johnson KA, Dick LM, Felix RJ, Jones KL. Birth outcomes in pregnant women taking fluoxetine. N Engl J Med. 1996;335: 1010-1015.

87. Ericson A, Källén B, Wiholm B. Delivery outcome after the use of antidepressants in early pregnancy. Eur J Clin Pharmacol. 1999;55: 503-508.

88. Goldstein DJ, Corbin LA, Sundell KL. Effects of first-trimester fluoxetine exposure on the newborn. Obstet Gynecol. 1997;89:713-718.

89. Kulin NA, Pastuszak A, Sage SR, et al. Pregnancy outcome following maternal use of the new selective serotonin reuptake inhibitors: a prospective controlled multicenter study. JAMA. 1998;279: 609-610.

90. Pastuszak A, Schick-Boschetto B, Zuber C, et al. Pregnancy outcome following first-trimester exposure to fluoxetine (Prozac). JAMA. 1993;269:2246-2248. 
91. Bobo WV, Epstein RA Jr, Hayes RM, et al. The effect of regulatory advisories on maternal antidepressant prescribing, 1995-2007: an interrupted time series study of 228,876 pregnancies. Arch Womens Ment Health. 2014;17:17-26.

92. Nordeng H, van Gelder MM, Spigset O, Koren G, Einarson A, Eberhard-Gran M. Pregnancy outcome after exposure to antidepressants and the role of maternal depression: results from the Norwegian Mother and Child Cohort Study. J Clin Psychopharmacol. 2012;32: 186-194.

93. Malm H, Artama M, Gissler M, Ritvanen A. Selective serotonin reuptake inhibitors and risk for major congenital anomalies. Obstet Gynecol. 2011;118:111-120.

94. Reis M, Källén B. Delivery outcome after maternal use of antidepressant drugs in pregnancy: an update using Swedish data. Psychol Med. 2010;40:1723-1733.

95. Einarson A, Choi J, Einarson TR, Koren G. Incidence of major malformations in infants following antidepressant exposure in pregnancy: results of a large prospective cohort study. Can J Psychiatry. 2009;54: 242-246.

96. Wichman CL, Moore KM, Lang TR, St Sauver JL, Heise RH Jr, Watson WJ. Congenital heart disease associated with selective serotonin reuptake inhibitor use during pregnancy. Mayo Clin Proc. 2009;84:23-27.

97. Davis RL, Rubanowice D, McPhillips H, et al. Risks of congenital malformations and perinatal events among infants exposed to antidepressant medications during pregnancy. Pharmacoepidemiol Drug Saf. 2007;16:1086-1094.

98. Källén BA, Otterblad OP. Maternal use of selective serotonin re-uptake inhibitors in early pregnancy and infant congenital malformations. Birth Defects Res A Clin Mol Teratol. 2007;79:301-308.

99. Louik C, Lin AE, Werler MM, Hernández-Díaz S, Mitchell AA. First-trimester use of selective serotonin-reuptake inhibitors and the risk of birth defects. $N$ Engl J Med. 2007;356:2675-2683.

100. Malm H, Klaukka T, Neuvonen PJ. Risks associated with selective serotonin reuptake inhibitors in pregnancy. Obstet Gynecol. 2005;106: 1289-1296.

101. Chambers CD, Hernandez-Diaz S, Van Marter LJ, et al. Selective serotonin-reuptake inhibitors and risk of persistent pulmonary hypertension of the newborn. N Engl J Med. 2006;354:579-587.

102. Hendrick V, Smith LM, Suri R, Hwang S, Haynes D, Altshuler L. Birth outcomes after prenatal exposure to antidepressant medication. Am J Obstet Gynecol. 2003;188:812-815.

103. Klieger-Grossmann C, Weitzner B, Panchaud A, et al. Pregnancy outcomes following use of escitalopram: a prospective comparative cohort study. J Clin Pharmacol. 2012;52:766-770.

104. Manakova E, Hubickova L. Antidepressant drug exposure during pregnancy. CZTIS small prospective study. Neuro Endocrinol Lett. 2011;32 Suppl 1:53-56.

105. Myles N, Newall H, Ward H, Large M. Systematic meta-analysis of individual selective serotonin reuptake inhibitor medications and congenital malformations. Aust N Z J Psychiatry. 2013;47:1002-1012.

106. Bar-Oz B, Einarson T, Einarson A, et al. Paroxetine and congenital malformations: meta-analysis and consideration of potential confounding factors. Clin Ther. 2007;29:918-926.

107. Grigoriadis S, VonderPorten EH, Mamisashvili L, et al. Antidepressant exposure during pregnancy and congenital malformations: is there an association? A systematic review and meta-analysis of the best evidence. J Clin Psychiatry. 2013;74:e293-e308.

108. Riggin L, Frankel Z, Moretti M, Pupco A, Koren G. The fetal safety of fluoxetine: a systematic review and meta-analysis. J Obstet Gynaecol Can. 2013;35:362-369.

109. Rahimi R, Nikfar S, Abdollahi M. Pregnancy outcomes following exposure to serotonin reuptake inhibitors: a meta-analysis of clinical trials. Reprod Toxicol. 2006;22:571-575.

110. Addis A, Koren G. Safety of fluoxetine during the first trimester of pregnancy: a meta-analytical review of epidemiological studies. Psychol Med. 2000;30:89-94.
111. Bakker MK, Kerstjens-Frederikse WS, Buys $\mathrm{CH}$, de Walle HE, de Jong-van den Berg LT. First-trimester use of paroxetine and congenital heart defects: a population-based case-control study. Birth Defects Res A Clin Mol Teratol. 2010;88:94-100.

112. Bérard A, Ramos E, Rey E, Blais L, St-André M, Oraichi D. First trimester exposure to paroxetine and risk of cardiac malformations in infants: the importance of dosage. Birth Defects Res B Dev Reprod Toxicol. 2007;80:18-27.

113. Merlob P, Birk E, Sirota L, et al. Are selective serotonin reuptake inhibitors cardiac teratogens? Echocardiographic screening of newborns with persistent heart murmur. Birth Defects Res A Clin Mol Teratol. 2009;85:837-841.

114. Pedersen LH, Henriksen TB, Vestergaard M, Olsen J, Bech BH. Selective serotonin reuptake inhibitors in pregnancy and congenital malformations: population based cohort study. BMJ. 2009;339:b3569.

115. Oberlander TF, Warburton W, Misri S, Riggs W, Aghajanian J, Hertzman C. Major congenital malformations following prenatal exposure to serotonin reuptake inhibitors and benzodiazepines using population-based health data. Birth Defects Res B Dev Reprod Toxicol. 2008;83:68-76.

116. Jimenez-Solem E, Andersen JT, Petersen M, et al. Exposure to selective serotonin reuptake inhibitors and the risk of congenital malformations: a nationwide cohort study. BMJ Open. 2012;2:e01148.

117. Källén B, Otterblad OP. Antidepressant drugs during pregnancy and infant congenital heart defect. Reprod Toxicol. 2006;21:221-222.

118. Einarson A, Pistelli A, DeSantis M, et al. Evaluation of the risk of congenital cardiovascular defects associated with use of paroxetine during pregnancy. Am J Psychiatry. 2008;165:749-752.

119. Reis M, Källén B. Combined use of selective serotonin reuptake inhibitors and sedatives/hypnotics during pregnancy: risk of relatively severe congenital malformations or cardiac defects. A register study. BMJ Open. 2013;3:e002166.

120. Diav-Citrin O, Shechtman S, Weinbaum D, et al. Paroxetine and fluoxetine in pregnancy: a prospective, multicentre, controlled, observational study. Br J Clin Pharmacol. 2008;66:695-705.

121. Cole JA, Modell JG, Haight BR, Cosmatos IS, Stoler JM, Walker AM. Bupropion in pregnancy and the prevalence of congenital malformations. Pharmacoepidemiol Drug Saf. 2007;16:474-484.

122. Ramos E, St-André M, Rey E, Oraichi D, Berard A. Duration of antidepressant use during pregnancy and risk of major congenital malformations. Br J Psychiatry. 2008;192:344-350.

123. Nulman I, Koren G. The safety of fluoxetine during pregnancy and lactation. Teratology. 1996;53:304-308.

124. Wogelius P, Nørgaard M, Gislum M, et al. Maternal use of selective serotonin reuptake inhibitors and risk of congenital malformations. Epidemiology. 2006;17:701-704.

125. Källén BA, Olausson PO. Maternal drug use in early pregnancy and infant cardiovascular defect. Reprod Toxicol. 2003;17:255-261.

126. Udechuku A, Nguyen T, Hill R, Szego K. Antidepressants in pregnancy: a systematic review. Aust N Z J Psychiatry. 2010;44:978-996.

127. Djulus J, Koren G, Einarson TR, et al. Exposure to mirtazapine during pregnancy: a prospective, comparative study of birth outcomes. J Clin Psychiatry. 2006;67:1280-1284.

128. Lennestal R, Källén B. Delivery outcome in relation to maternal use of some recently introduced antidepressants. J Clin Psychopharmacol. 2007;27:607-613.

129. Sackett JC, Weller RA, Weller EB. Selective serotonin reuptake inhibitor use during pregnancy and possible neonatal complications. Curr Psychiatry Rep. 2009;11:253-257.

130. Adams M, Hudgins L. The importance of minor anomalies in the evaluation of the newborn. Neoreviews. 2003;4:e99-e104.

131. Walsh-Sukys MC, Tyson JE, Wright LL, et al. Persistent pulmonary hypertension of the newborn in the era before nitric oxide: practice variation and outcomes. Pediatrics. 2000;105:14-20.

132. Hernández-Díaz S, Van Marter LJ, Werler MM, Louik C, Mitchell AA. Risk factors for persistent pulmonary hypertension of the newborn. Pediatrics. 2007;120:e272-e282. 
133. Källén B, Olausson PO. Maternal use of selective serotonin re-uptake inhibitors and persistent pulmonary hypertension of the newborn. Pharmacoepidemiol Drug Saf. 2008;17:801-806.

134. US Food and Drug Administration. Public health advisory: treatment challenges of depression in pregnancy and the possibility of persistent pulmonary hypertension in newborns. 2013. Available from: http:// www.fda.gov/drugs/drugsafety/postmarketdrugsafetyinformationforp atientsandproviders/drugsafetyinformationforheathcareprofessionals/ publichealthadvisories/ucm124348.htm. Accessed August 6, 2014

135. Andrade SE, McPhillips H, Loren D, et al. Antidepressant medication use and risk of persistent pulmonary hypertension of the newborn. Pharmacoepidemiol Drug Saf. 2009;18:246-252.

136. Wilson KL, Zelig CM, Harvey JP, Cunningham BS, Dolinsky BM, Napolitano PG. Persistent pulmonary hypertension of the newborn is associated with mode of delivery and not with maternal use of selective serotonin reuptake inhibitors. Am J Perinatol. 2011;28:19-24.

137. Kieler H, Artama M, Engeland A, et al. Selective serotonin reuptake inhibitors during pregnancy and risk of persistent pulmonary hypertension in the newborn: population based cohort study from the five Nordic countries. BMJ. 2012;344:d8012.

138. US Food and Drug Administration. FDA drug safety communication: selective serotonin reuptake inhibitor (SSRI) antidepressant use during pregnancy and reports of a rare heart and lung condition in newborn babies. 2011. Available from: http://www.fda.gov/drugs/drugsafety/ ucm283375.htm. Accessed August 6, 2014.

139. Kalra S, Einarson A, Koren G. Taking antidepressants during late pregnancy. How should we advise women? Can Fam Physician. 2005;51:1077-1078.

140. Moses-Kolko EL, Bogen D, Perel J, et al. Neonatal signs after late in utero exposure to serotonin reuptake inhibitors: literature review and implications for clinical applications. JAMA. 2005;293:2372-2383.

141. Isbister GK, Dawson A, Whyte IM, Prior FH, Clancy C, Smith AJ. Neonatal paroxetine withdrawal syndrome or actually serotonin syndrome? Arch Dis Child Fetal Neonatal Ed. 2001;85:F147-F148.

142. Oberlander TF, Misri S, Fitzgerald CE, Kostaras X, Rurak D, Riggs W. Pharmacologic factors associated with transient neonatal symptoms following prenatal psychotropic medication exposure. J Clin Psychiatry. 2004;65:230-237.

143. Way CM. Safety of newer antidepressants in pregnancy. Pharmacotherapy. 2007;27:546-552.

144. Misri S, Sivertz K. Tricyclic drugs in pregnancy and lactation: a preliminary report. Int J Psychiatry Med. 1991;21:157-171.

145. Schimmell MS, Katz EZ, Shaag Y, Pastuszak A, Koren G. Toxic neonatal effects following maternal clomipramine therapy. $J$ Toxicol Clin Toxicol. 1991;29:479-484.

146. Cowe L, Lloyd DJ, Dawling S. Neonatal convulsions caused by withdrawal from maternal clomipramine. $\mathrm{Br} \mathrm{Med} J$ (Clin Res Ed). 1982;284:1837-1838.

147. Ferreira E, Carceller AM, Agogue C, et al. Effects of selective serotonin reuptake inhibitors and venlafaxine during pregnancy in term and preterm neonates. Pediatrics. 2007;119:52-59.

148. Ter Horst PG, Jansman FG, van Lingen RA, Smit JP, de Jong-van den Berg LT, Brouwers JR. Pharmacological aspects of neonatal antidepressant withdrawal. Obstet Gynecol Surv. 2008;63:267-279.

149. Boucher N, Koren G, Beaulac-Baillargeon L. Maternal use of venlafaxine near term: correlation between neonatal effects and plasma concentrations. Ther Drug Monit. 2009;31:404-409.

150. Lattimore KA, Donn SM, Kaciroti N, Kemper AR, Neal CR Jr, Vazquez DM. Selective serotonin reuptake inhibitor (SSRI) use during pregnancy and effects on the fetus and newborn: a meta-analysis. J Perinatol. 2005;25:595-604.

151. Källén B. Neonate characteristics after maternal use of antidepressants in late pregnancy. Arch Pediatr Adolesc Med. 2004;158:312-316.

152. Grigoriadis S, VonderPorten EH, Mamisashvili L, et al. The effect of prenatal antidepressant exposure on neonatal adaptation: a systematic review and meta-analysis. J Clin Psychiatry. 2013;74: e309-e320.
153. Casper RC, Fleisher BE, Lee-Ancajas JC, et al. Follow-up of children of depressed mothers exposed or not exposed to antidepressant drugs during pregnancy. J Pediatr. 2003;142:402-408.

154. Maschi S, Clavenna A, Campi R, Schiavetti B, Bernat M, Bonati M. Neonatal outcome following pregnancy exposure to antidepressants: a prospective controlled cohort study. BJOG. 2008;115:283-289.

155. Grigoriadis S, Mamisashvili L, Ross LE. Achieving the balance: treating depressed pregnant women with antidepressants. J Clin Psychiatry. 2013;74:375-376.

156. Koren G, Nordeng H. Antidepressant use during pregnancy: the benefit-risk ratio. Am J Obstet Gynecol. 2012;207:157-163.

157. US Food and Drug Administration. FDA MedWatch drug alert on Effexor and SSRIs. 2004. Available from: http://www.fda.gov/Safety/ MedWatch/SafetyInformation/SafetyAlertsforHumanMedicalProduc ts/ucm154975.htm. Accessed August 6, 2014.

158. Warburton W, Hertzman C, Oberlander TF. A register study of the impact of stopping third trimester selective serotonin reuptake inhibitor exposure on neonatal health. Acta Psychiatr Scand. 2010;121: 471-479

159. Engle WA. Morbidity and mortality in late preterm and early term newborns: a continuum. Clin Perinatol. 2011;38:493-516.

160. Shapiro-Mendoza CK, Lackritz EM. Epidemiology of late and moderate preterm birth. Semin Fetal Neonatal Med. 2012;17:120-125.

161. Ross LE, Grigoriadis S, Mamisashvili L, et al. Selected pregnancy and delivery outcomes after exposure to antidepressant medication: a systematic review and meta-analysis. JAMA Psychiatry. 2013;70: 436-443.

162. Simon GE, Cunningham ML, Davis RL. Outcomes of prenatal antidepressant exposure. Am J Psychiatry. 2002;159:2055-2061.

163. Lund N, Pedersen L, Henriksen T. SSRI exposure in utero and pregnancy outcome. J Matern Fetal Neonatal Med. 2006;19:45.

164. Wen SW, Yang Q, Garner P, et al. Selective serotonin reuptake inhibitors and adverse pregnancy outcomes. Am J Obstet Gynecol. 2006;194: 961-966

165. Lewis AJ, Galbally M, Opie G, Buist A. Neonatal growth outcomes at birth and one month postpartum following in utero exposure to antidepressant medication. Aust N Z J Psychiatry. 2010;44:482-487.

166. Pearson KH, Nonacs RM, Viguera AC, et al. Birth outcomes following prenatal exposure to antidepressants. J Clin Psychiatry. 2007;68: 1284-1289.

167. Einarson A, Choi J, Einarson TR, Koren G. Adverse effects of antidepressant use in pregnancy: an evaluation of fetal growth and preterm birth. Depress Anxiety. 2010;27:35-38.

168. Palmsten K, Hernández-Díaz S. Can nonrandomized studies on the safety of antidepressants during pregnancy convincingly beat confounding, chance, and prior beliefs? Epidemiology. 2012;23:686-688.

169. Davalos DB, Yadon CA, Tregellas HC. Untreated prenatal maternal depression and the potential risks to offspring: a review. Arch Womens Ment Health. 2012;15:1-14.

170. Suri R, Altshuler L, Hellemann G, Burt VK, Aquino A, Mintz J. Effects of antenatal depression and antidepressant treatment on gestational age at birth and risk of preterm birth. Am J Psychiatry. 2007;164: 1206-1213.

171. Yonkers KA, Norwitz ER, Smith MV, et al. Depression and serotonin reuptake inhibitor treatment as risk factors for preterm birth. Epidemiology. 2012;23:677-685.

172. García-Enguídanos A, Calle ME, Valero J, Luna S, Domínguez-Rojas V. Risk factors in miscarriage: a review. Eur J Obstet Gynecol Reprod Biol. 2002;102:111-119.

173. Goddijn M, Leschot NJ. Genetic aspects of miscarriage. Baillieres Best Pract Res Clin Obstet Gynaecol. 2000;14:855-865.

174. Hemels ME, Einarson A, Koren G, Lanctot KL, Einarson TR Antidepressant use during pregnancy and the rates of spontaneous abortions: a meta-analysis. Ann Pharmacother. 2005;39:803-809.

175. Einarson A, Fatoye B, Sarkar M, et al. Pregnancy outcome following gestational exposure to venlafaxine: a multicenter prospective controlled study. Am J Psychiatry. 2001;158:1728-1730. 
176. Chun-Fai-Chan B, Koren G, Fayez I, et al. Pregnancy outcome of women exposed to bupropion during pregnancy: a prospective comparative study. Am J Obstet Gynecol. 2005;192:932-936.

177. Einarson A, Choi J, Einarson TR, Koren G. Rates of spontaneous and therapeutic abortions following use of antidepressants in pregnancy: results from a large prospective database. J Obstet Gynaecol Can. 2009;31:452-456.

178. Nakhai-Pour HR, Broy P, Bérard A. Use of antidepressants during pregnancy and the risk of spontaneous abortion. CMAJ. 2010;182: 1031-1037.

179. Einarson A, Bonari L, Voyer-Lavigne S, et al. A multicentre prospective controlled study to determine the safety of trazodone and nefazodone use during pregnancy. Can J Psychiatry. 2003;48:106-110.

180. McElhatton PR, Garbis HM, Elefant E, et al. The outcome of pregnancy in 689 women exposed to therapeutic doses of antidepressants. A collaborative study of the European Network of Teratology Information Services (ENTIS). Reprod Toxicol. 1996;10: 285-294.

181. Tuccori M, Testi A, Antonioli L, et al. Safety concerns associated with the use of serotonin reuptake inhibitors and other serotonergic/ noradrenergic antidepressants during pregnancy: a review. Clin Ther. 2009;31 Pt 1:1426-1453.

182. Kjaersgaard MI, Parner ET, Vestergaard M, et al. Prenatal antidepressant exposure and risk of spontaneous abortion - a population-based study. PLoS One. 2013;8:e72095.

183. Walfisch A, Sermer C, Matok I, Einarson A, Koren G. Perception of teratogenic risk and the rated likelihood of pregnancy termination: association with maternal depression. Can J Psychiatry. 2011;56:761-767.

184. Bonari L, Pinto N, Ahn E, Einarson A, Steiner M, Koren G. Perinatal risks of untreated depression during pregnancy. Can J Psychiatry. 2004;49:726-735.

185. Oberlander TF, Warburton W, Misri S, Aghajanian J, Hertzman C. Effects of timing and duration of gestational exposure to serotonin reuptake inhibitor antidepressants: population-based study. $\mathrm{Br} J$ Psychiatry. 2008;192:338-343.

186. Heikkinen T, Ekblad U, Kero P, Ekblad S, Laine K. Citalopram in pregnancy and lactation. Clin Pharmacol Ther. 2002;72:184-191.

187. Sivojelezova A, Shuhaiber S, Sarkissian L, Einarson A, Koren G. Citalopram use in pregnancy: prospective comparative evaluation of pregnancy and fetal outcome. Am J Obstet Gynecol. 2005;193: 2004-2009.

188. Costei AM, Kozer E, Ho T, Ito S, Koren G. Perinatal outcome following third trimester exposure to paroxetine. Arch Pediatr Adolesc Med. 2002;156:1129-1132.

189. Nulman I, Rovet J, Stewart DE, et al. Neurodevelopment of children exposed in utero to antidepressant drugs. $N$ Engl J Med. 1997;336: 258-262.

190. Cohen LS, Heller VL, Bailey JW, Grush L, Ablon JS, Bouffard SM. Birth outcomes following prenatal exposure to fluoxetine. Biol Psychiatry. 2000;48:996-1000.

191. Suri R, Altshuler L, Hendrick V, Rasgon N, Lee E, Mintz J. The impact of depression and fluoxetine treatment on obstetrical outcome. Arch Womens Ment Health. 2004;7:193-200.

192. Laine K, Heikkinen T, Ekblad U, Kero P. Effects of exposure to selective serotonin reuptake inhibitors during pregnancy on serotonergic symptoms in newborns and cord blood monoamine and prolactin concentrations. Arch Gen Psychiatry. 2003;60:720-726.

193. Weinberger AH, Mazure CM, Morlett A, McKee SA. Two decades of smoking cessation treatment research on smokers with depression: 1990-2010. Nicotine Tob Res. 2013;15:1014-1031.

194. Davidson KM, Ritson EB. The relationship between alcohol dependence and depression. Alcohol Alcohol. 1993;28:147-155.

195. Bodnar LM, Wisner KL, Moses-Kolko E, Sit DK, Hanusa BH. Prepregnancy body mass index, gestational weight gain, and the likelihood of major depressive disorder during pregnancy. J Clin Psychiatry. 2009; 70:1290-1296.
196. Wisner KL, Bogen DL, Sit D, et al. Does fetal exposure to SSRIs or maternal depression impact infant growth? Am J Psychiatry. 2013;170: 485-493.

197. Beck AT, Steer RA, Brown GK. Beck Depression Inventory. 2nd ed. San Antonio: Psychological Corporation; 1996.

198. Sibai BH. Diagnosis and management of gestational hypertension and preeclampsia. Obstet Gynecol. 2003;102:181-192.

199. Podymow T, August P. Hypertension in pregnancy. Adv Chronic Kidney Dis. 2007;14:178-190.

200. Grofton EN, Capewell V, Natale R, Gratton RJ. Obstetrical intervention rates and maternal and neonatal outcomes of women with gestational hypertension. Am J Obstet Gynecol. 2001;185:798-803.

201. Steegers EA, von Dadelszen P, Duvekot JJ, Pijneborg R. Pre-eclampsia. Lancet. 2010;376:631-644.

202. Qiu C, Williams MA, Calderon-Margalit R, Cripe SM, Sorensen TK. Preeclampsia risk in relation to maternal mood and anxiety disorders diagnosed before or during early pregnancy. Am J Hypertens. 2009;22:397-402.

203. Kurki T, Hiilesmaa V, Raitasalo R, Mattila H, Ylikorkala O. Depression and anxiety in early pregnancy and risk for preeclampsia. Obstet Gynecol. 2000;95:487-490.

204. Qiu C, Sanchez SE, Lam N, Garcia P, Williams MA. Associations of depression and depressive symptoms with preeclampsia: results from a Peruvian case-control study. BMC Womens Health. 2007;7:15.

205. Toh S, Mitchell AA, Louik C, Werler MM, Chambers CD, Hernández-Díaz S. Selective serotonin reuptake inhibitor use and risk of gestational hypertension. Am J Psychiatry. 2009;166:320-328.

206. De Vera MA, Bérard A. Antidepressant use during pregnancy and the risk of pregnancy-induced hypertension. Br J Clin Pharmacol. 2012;74:362-369.

207. Palmsten K, Setoguchi S, Margulis AV, Patrick AR, Hernández-Díaz S. Elevated risk of preeclampsia in pregnant women with depression: depression or antidepressants? Am J Epidemiol. 2012;175:988-997.

208. Thase M. Effects of venlafaxine on blood pressure: a meta-analysis of original data from 3,744 depressed patients. J Clin Psychiatry. 1998;59:502-509.

209. Walsh BT, Hadigan CM, Wong LM. Increased pulse and blood pressure associated with desipramine treatment of bulimia nervosa. J Clin Psychopharmacol. 1992;123:163-168.

210. Goldberg JF, Ernst CL. Hypertension. In: Golderg JF, Ernst CL, editors. Managing the Side Effects of Psychotropic Medications. Washington: American Psychiatric; 2012:137-138.

211. Reebye PN, Morison SJ, Panikkar H, Misri S, Grunau RE. Affect expression in prenatally psychotropic exposed and nonexposed mother-infant dyads. Infant Ment Health J. 2002;23:403-416.

212. Oberlander TF, Reebye P, Misri S, Papsdorf M, Kim J, Grunau RE. Externalizing and attentional behaviors in children of depressed mothers treated with a selective serotonin reuptake inhibitor antidepressant during pregnancy. Arch Pediatr Adolesc Med. 2007;161: 22-29.

213. Pedersen LH, Henriksen TB, Olsen J. Fetal exposure to antidepressants and normal milestone development at 6 and 19 months of age. Pediatrics. 2010;125:e600-e608.

214. Sie SD, Wennink JM, van Driel JJ, et al. Maternal use of SSRIs, SNRIs and NaSSAs: practical recommendations during pregnancy and lactation. Arch Dis Child Fetal Neonatal Ed. 2012;97:F472-F476.

215. Vesga-López O, Blanco C, Keyes K, Olfson M, Grant BF, Hasin DS. Psychiatric disorders in pregnant and postpartum women in the United States. Arch Gen Psychiatry. 2008;65:805-815.

216. Wickramaratne P, Gameroff MJ, Pilowsky DJ, et al. Children of depressed mothers 1 year after remission of maternal depression: findings from the STAR*D-Child study. Am J Psychiatry. 2011;168: 593-602.

217. Foster CE, Webster MC, Weissman MM, et al. Remission of maternal depression: relations to family functioning and youth internalizing and externalizing symptoms. J Clin Child Adolesc Psychol. 2008;37: 714-724. 
218. Coiro MJ, RIley A, Broitman M, Miranda J. Effects on children of treating their mothers' depression: results of a 12-month follow-up. Psychiatr Serv. 2012;63:357-363.

219. Gunlicks ML, Weissman MM. Change in child psychopathology with improvement in parental depression: a systematic review. J Am Acad Child Adolesc Psychiatry. 2008;47:379-389.
220. Wisner KL, Zarin DA, Holmboe ES, et al. Risk-benefit decision making for treatment of depression during pregnancy. Am J Psychiatry. 2000;157:1933-1940.

221. Chaudron LH. Complex challenges in treating depression during pregnancy. Am J Psychiatry. 2013;170:12-20.

\section{Publish your work in this journal}

Drug, Healthcare and Patient Safety is an international, peer-reviewed open-access journal exploring patient safety issues in the healthcare continuum from diagnostic and screening interventions through to treatment, drug therapy and surgery. The journal is characterized by the rapic reporting of reviews, original research, clinical, epidemiological and
Dovepress

post-marketing surveillance studies, risk management, health literacy and educational programs across all areas of healthcare delivery. The manuscript management system is completely online and includes a very quick and fair peer-review system. Visit http://www.dovepress.com/ testimonials.php to read real quotes from published authors.

Submit your manuscript here: http://www.dovepress.com/drug-healthcare-and-patient-safety-journal 